\title{
The Evolution of Entrepreneurial Spirit and the Process of Development
}

\author{
November 22, 2006
}

\begin{abstract}
This research suggests that the evolution of entrepreneurial spirit played a significant role in the process of economic development and the evolution of inequality within and across societies. The study argues that entrepreneurial spirit evolved non-monotonically in the course of human history. In early stages of development, the rise in income generated an evolutionary advantage to entrepreneurial, growth promoting traits and their increased representation accelerated the pace of technological advancements and the process of economic development. Natural selection therefore had magnified growth promoting activities in relatively wealthier economies as well as within the upper segments of societies, enlarging the income gap within as well as across societies. In mature stages of development, however, non-entrepreneurial individuals gained an evolutionary advantage, diminishing the growth potential of advanced economies and contributing to the convergence of the intermediate level economies to the advanced ones.

Keywords: Risk Aversion, Growth, Technological Progress, Evolution, Natural Selection

JEL classification Numbers: O11, O14, O33, O40, J11, J13.
\end{abstract}




\section{Introduction}

This research examines the reciprocal interplay between the evolution of entrepreneurial spirit and the process of development. The analysis suggests that the prevalence of entrepreneurial traits evolved non-monotonically in the course of human history. In the early stages of development risk-tolerant, growth promoting entrepreneurial traits generated an evolutionary advantage and their increased representation accelerated the pace of technological advancements, contributing significantly to the process of development and the transition from stagnation to growth. As economies matured, however, this evolutionary pattern was reversed. Entrepreneurial individuals had an evolutionary disadvantage and the growth potential of economies diminished. ${ }^{1}$

The study argues that historical variations in geographical, environmental and social factors affected the pace of this evolutionary process and thus the prevalence of growth promoting entrepreneurial traits across economies, contributing to the sustained contemporary differences in productivity and income per-capita across countries. Interestingly, the theory suggests that in early stages of development, the forces of natural selection had magnified growth promoting activities in relatively wealthier economies, enlarging the gap in income per capita between societies. However, as the growth process matured in advanced economies, the forces of natural selection contributed to a convergence of the intermediate level economies to the advanced ones. It diminished the growth potential of the most advanced economies, and enhanced the growth process of the intermediate ones. Thus, unlike the commonly underlined forces for economic convergence (i.e., higher returns to investments in human capital, physical capital and technological adoption for the laggard countries), the research proposes that convergence is triggered by a higher prevalence of growth promoting entrepreneurial traits in the middle income economies. Moreover, the analysis demonstrates that in the least advanced economies, selection of growth promoting traits has been delayed, contributing to the persistence of poverty.

Additionally, the predictions of the proposed theory provide further understanding of the path of income inequality within a society over time. Consistent with the observed pattern of inequality in the process of development (Galor (2005)), the study suggests that in early stages of development inequality widens due to a more rapid selection of entrepreneurial risk tolerant individuals among the elites. However as the economy matures, inequality subsides due to the

\footnotetext{
${ }^{1}$ The theory is perfectly applicable for either social or genetic intergenerational transmission of traits. Cultural transmission is likely to be more rapid. The interaction between cultural and genetic evolution is explored by Boyd and Richardson [1985] and Cavalli-Sforza and Feldman [1981]. A cultural transmission of preferences was recently explored by Bisin and Verdier [2000].
} 
increased representation of entrepreneurial, risk tolerant individuals among the middle and the lower class. In particular, this prediction is consistent with the class origin of entrepreneurs during the industrial revolution. The failure of the landed aristocracy to lead the risky process of industrialization could be attributed to the low representation of risk tolerant individuals within the landed gentry, and the prevalence of growth promoting entrepreneurial traits among the middle and even the lower class (e.g., offspring of artisans and yeomen).

This research develops an evolutionary growth theory that underlines the importance of the evolution of entrepreneurial spirit in the transition from stagnation to growth. It constructs an overlapping-generations economy that due to the forces of natural selection evolves endogenously from a Malthusian epoch into a state of sustained economic growth. The growth process is fueled by technological progress that is affected positively by the level of income per capita as well as by the prevalence of risk-tolerant entrepreneurial individuals in the economy. ${ }^{2}$ Variations in entrepreneurial spirit among individuals are modeled as differences in the degree of risk aversion with respect to consumption. These variations are linked, in our formulation, to differences in the elasticity of substitution between consumption and fertility, reflecting the sensitivity of individuals to changes in relative prices and capturing therefore their responsiveness to arbitrage opportunities. These differences in the degree of risk aversion with respect to consumption across individuals affect their reproductive success differentially and are transmitted across generations, either genetically or culturally. At early stages of development, countries that are observed to be in a stationary equilibrium undergo a change in the (latent) distribution of entrepreneurial spirit. A low degree of entrepreneurial spirit has an adverse effect on fertility and reproductive success, raising the frequency of the entrepreneurial, risk-tolerant, growth promoting individuals in the economy and stimulating the growth process. However, as economies mature, higher degree of risk aversion (i.e., lower level of entrepreneurial spirit) has a beneficial effect on reproductive success, diminishing the growth potential of the economy. The non-monotonic effect of entrepreneurial spirit on fertility across different levels of income per capita is the driving force behind the changing distribution of the entrepreneurial, risk tolerant individuals in the population along the path of economic development. It contributes to the non-monotonic effect of natural selection on inequality across nations, stimulating divergence in early stages of development and convergence in more mature phases.

The reversal in the evolutionary advantage of the risk-tolerant entrepreneurial types

\footnotetext{
${ }^{2}$ Technological adoption and creation is associated with uncertainty, and a population with more risk-tolerant individuals would engage more frequently in innovative risky projects, thus outperforming technologically a similar size population comprised of more risk-averse individuals.
} 
stems from the effect of the level of income on the relative cost of consumption and child rearing. Variations in risk aversion with respect to consumption are reflected at differences in the elasticity of substitution between consumption and fertility. The lower is the degree of risk aversion (i.e., the smaller is the concavity of the utility function with respect to consumption) the higher is the elasticity of substitution and thus the lower is the curvature of the indifference curves between consumption and fertility. ${ }^{3}$ As the economy progresses and wage income increases, the opportunity cost of child rearing increases relative to consumption. Consequently, at sufficiently low levels of income the cost of children (whose production is time-intensive) is lower than that of consumption and the less risk averse individuals whose choices are more responsive to the relative prices, optimally allocate more resources towards child rearing, and the representation of their type increases in the population over time. As the economy develops and wage income increases, the cost of raising children is eventually higher than the cost of consumption. The less risk averse individuals, who are more responsive in their choices to relative prices, optimally allocate more resources towards consumption and less toward children. Hence, the more risk averse individuals allocate relatively more resources towards fertility and gain the evolutionary advantage. ${ }^{4}$

Interestingly, the forces of natural selection are critical for the escape from the Malthusian epoch. In their absence the economy will remain indefinitely in a Malthusian equilibrium. Namely, if the degree of risk tolerance is not hereditary and the distribution of types remains unchanged over time, the level of income per capita will be stationary at a level where consumption is at the subsistence level and fertility is at replacement level. Technological advancement will be counterbalanced by an increase in population growth, whereas adverse technological shocks will be offset by population decline and the long-run income per-capita will remain unchanged.

The predictions of the theory regarding the reversal in the evolutionary advantage of entrepreneurial, risk tolerant individuals in more advanced stages of development could be examined based on the effect of the degree of risk aversion on fertility choices in contemporary developed and underdeveloped economies. Existing evidence is consistent with the proposed

\footnotetext{
${ }^{3}$ This relationship reverses at very low levels of income specifically in the early part of the income range where child rearing is relatively less expensive than own consumption. This temporary reversal only accentuates the evolutionary advantage of the risk tolerant trait at early stages of development. Using a utility function where the degree of risk aversion is monotonically and inversely related to the elasticity of substitution, as considered in one of the cases in the appendix, yields qualitatively similar predictions.

${ }^{4}$ At the level of income where the cost of children is equal to the cost of consumption, consumption and fertility choices are identical across different types of individuals.
} 
hypothesis suggesting that entrepreneurial propensity proxied by risk tolerance is positively correlated with the number of children in less developed economies and negatively in developed economies. ${ }^{5}$ Wik et al. (2004), using an experimental gambling method, derive a measure of risk aversion for agricultural household heads in Northern Zambia. They find that larger households are negatively and significantly correlated with the degree of risk aversion, controlling for sex, age, income, education, farm area, etc. ${ }^{6}$ Similarly negative and statistically significant association between the size of the household and the degree of risk aversion is found among rural households in Indonesia, using a gambling experimental approach (Miyata (2003)). Consistently with the proposed theory, the opposite correlations are found in developed countries. Feinerman et al. (1996) report that family size is positively correlated with risk aversion among farmers in Israel, ${ }^{7}$ and Dohmen et al. (2005) using a German survey designed to assess the correlation between the number of children on the degree of risk taking in several realms of life (e.g., investment and career choices, health, driving, etc.) find that lower willingness to undertake risk is associated with more children.

The theory rests upon two fundamental building blocks: the positive effect on technological change of the frequency of individuals with an entrepreneurial spirit (e.g., risk-tolerant, highly responsive to incentives and relative prices), and the heritability of this entrepreneurial spirit. The positive association between the frequency of the entrepreneurial individuals in the population on the rate of technological progress and economic growth is well documented in the literature, and is at the foundation of Schumpeterian viewpoint (e.g., Schumpeter (1934), Aghion and Howitt (1992)) where the role of entrepreneurs is instrumental in the process of innovations. ${ }^{8}$ In particular, the role of risk taking behavior in facilitating innovation and technological adoption in the industrial as well as the agricultural sectors is well documented. Van Praag and Cramer (2001) using Dutch data find that risk aversion is negatively associated with the probability of entrepreneurial activity. Knight et al. (2003) find that risk aversion

\footnotetext{
${ }^{5}$ Several surveys (e.g., gambling experiments with real or hypothetical payoffs) have been conducted in developing countries measuring attitudes towards risk among individuals in rural areas and relating them to socioeconomic characteristics. The measure of risk aversion in the reported studies is the partial relative risk aversion coefficient which relates both to the relative risk aversion and the absolute risk aversion (Bar-Shira et al (1997)).

${ }^{6}$ In the absence of direct measure of the number of children, the size of the household is the variable of interest because it correlates closely with number of children produced by the household. Reassuringly, extended families do not drive the results.

${ }^{7}$ In absence of comparable data on income and wealth across groups in these studies, educational differences may proxy for economic development. Average education of farmers in the Mexicans sample was about 2.5 years, in Zambia 5.2 and Indonesia 5.7. In contrast, average education of Israeli farmers was 12 years.

${ }^{8}$ It is also related to the Boserupian hypothesis according to which the struggle for survival in the Malthusian epoch generated the inducement for inventions (Boserup (1965)).
} 
among peasants in Ethiopia is associated with a reduction in the probability of innovations and adoption of existing technologies. ${ }^{9}$ Audretsch and Thurik (2001) find that increases in entrepreneurial activity, within countries and regions in the OECD, result in higher subsequent growth rates and a reduction of unemployment. ${ }^{10}$ Similarly, Audretsch and Keilbach (2005) document a large positive impact of entrepreneurship on regional labor productivity in Germany.

Furthermore, consistent with the supposition that entrepreneurial spirit is heritable, evidence described in the next section, suggests that the trait of "novelty seeking" has been subjected to a selection process in the recent past. More generally, evidence suggests that evolutionary processes in the composition of existing genetic traits may be rather rapid, and major evolutionary changes have occurred in the human population over the time period that is the focus of this study. ${ }^{11}$ Voight et al. (2006) detected about 700 regions of the human genome where genes appear to have been reshaped by natural selection within the last 5,000 to 15,000 years. Moreover, a recent study by Mekel-Bobrov et. al (2005) reports that a variant of the gene ASPM (a specific regulator of brain size in the lineage leading to Homo sapiens) arose in humans merely about 5800 years ago and has since swept to high frequency under strong positive selection. Other notable evidence suggests that lactose tolerance was developed among European and Near Easterners since the domestication of dairy animals in the course of the Neolithic revolution, whereas in regions that were exposed to dairy animals in later stages, a larger proportion of the adult population suffers from lactose intolerance. Furthermore, genetic immunity to malaria provided by the sickle cell trait is prevalent among descendents of Africans whose engagement in agriculture improved the breeding ground for mosquitoes and thereby raised the incidence of malaria, whereas this trait is absent among descendents of

\footnotetext{
${ }^{9}$ Among other agricultural studies Grisley and Kellog (1987) find that a decline in the degree of risk aversion of farmers in Thailand is associated with higher expected variation of rice yields. Similarly, Moscardi and de Janvri (1977) document that higher risk aversion among peasants in Mexico is associated with a reduction in the amount of the fertilizer used below the optimal level.

${ }^{10}$ Entrepreneurial activity is proxied by the relative share of economic activity accounted for by small firms, and the self-employment rate.

${ }^{11}$ There are numerous examples of rapid evolutionary changes among various species. The color change that peppered moths underwent during the 19th century is a classic example of evolution in nature (See Kettlewell 1973). Before the Industrial Revolution light-colored English peppered moths blended with the lichen-covered bark of trees. By the end of the 19th century a black variant of the moth, first recorded in 1848, became far more prevalent than the lighter varieties in areas in which industrial carbon removed the lichen and changed the background color. Hence, a significant evolutionary change occurred within a time period which corresponds to only hundreds of generations. Moreover, evidence from Daphne Major in the Galapagos suggests that significant evolutionary changes in the distribution of traits among Darwin's Finches occurred within few generations due to a major drought (Grant and Grant 1989). Other evidence, including the dramatic changes in the color patterns of guppies within 15 generations due to changes in the population of predators, are surveyed by Endler (1986).
} 
nearby populations that have not made the transition to agriculture. ${ }^{12}$

\section{$1.1 \quad$ Related Literature}

The transition from stagnation to growth and the associated phenomenon of the great divergence have been the subject of intensive research in the growth literature in recent years. ${ }^{13}$ It has been increasingly recognized that the understanding of the contemporary growth process would be fragile and incomplete unless growth theory could be based on proper micro-foundations that would reflect the various qualitative aspects of the growth process and their central driving forces. Moreover, it has become apparent that a comprehensive understanding of the hurdles faced by less developed economies in reaching a state of sustained economic growth would be futile unless the factors that prompted the transition of the currently developed economies into a state of sustained economic growth could be identified and their implications would be modified to account for the differences in the growth structure of less developed economies in an interdependent world.

Despite the existence of compelling evidence about the interaction between human evolution and the process of economic development, only few attempts have been made to examine this reciprocal relationship. ${ }^{14}$ This exploration is likely to revolutionize the understanding of the impact of major economic transitions on human evolution and the effect of the forces of natural selection, via their impact on the composition of human traits, on the pace of the process of economic development. ${ }^{15}$ A notable exception is a study by Galor and Moav (2002) that explores the reciprocal interaction between the process of economic development and human evolution. It suggests that the Neolithic revolution and the subsequent epoch of Malthusian stagnation triggered a selection of traits of higher valuation for offspring quality, that ultimately played a significant role in the transition from stagnation to growth. Lagerlof (2005) examines the interaction between the evolution of body size and the process of development since the emergence of the Homo sapiens. Spolaore and Wacziarg (2005) examine the effect of differences in human characteristics that are transmitted across generations on the diffusion of development across countries over the very long run. Other studies have abstracted from the reciprocal interaction between human evolution and the process of development and have focused on the

\footnotetext{
${ }^{12}$ See Levingston (1958), Weisenfeld (1967) and Durham (1982).

${ }^{13}$ See, Galor and Weil (1999, 2000), Lucas (2002), Galor and Moav (2002), Hansen and Prescott (2002), Doepke (2004), Galor (2005), Lagerlof (2006).

${ }^{14}$ The role of evolutionary process in economics and in particular in the context of technological change is explored by Mokyr (1998, 2005, 2006).

${ }^{15}$ For the impact of hereditary trait on the process of development, see Jones and Schneider (2006).
} 
effect of the economic environment on the evolution of human characteristics. Ofek (2001) and Saint Paul (2003) examine the effect of the emergence of markets on the evolution of heterogeneity in the human population. Galor and Moav (2004) study the effect of the Neolithic Revolution and the associated rise in population density on the evolution of life expectancy, and Borghans, Borghans and ter Weel (2006) explore the effect of human cooperation on the evolution of Major Histocompatibility Complex (MHC). ${ }^{16}$

The implications of the theory for the class origin of entrepreneurs during the Industrial Revolution is complementary to those of Doepke and Zilliboti (2005a, 2005b). Their theory suggests that a new class of entrepreneurs rising from the middle classes, imbued with ethics emphasizing patience and savings, proved most capable of profiting from new economic opportunities, and eventually surpassed the pre-industrial elite. Similarly, we argue that the failure of the landed aristocracy to lead the risky process of industrialization could be attributed to the effect of Darwinian selection on the low representation of entrepreneurial, risk tolerant individuals within the landed gentry, and the prevalence of risk tolerant individuals among the middle and even the lower classes. Moreover, the existence of primogeniture in preindustrial Europe limited social and income mobility between the landed gentry and the other classes (Bertocchi (2006)), allowing the forces of natural selection to differentially affect the evolution of risk aversion across classes, leading to the observed variations in the involvement of the upper and the middle class in the Industrial Revolution ${ }^{17}$

\subsection{Genetic Evidence About the Evolution of Risk Aversion}

This section provides an overview of the psychological and biological literature that links entrepreneurial activities to heritable genetic traits, and it interprets the evolutionary patterns

\footnotetext{
${ }^{16}$ The evolution of preferences, in a given economic environment, has been explored in the economic literature, as surveyed by Weibull (1995) and Bowles (1998), and is explored more recently by Weibull and Salomonsson (2005). In particular, in contrast to our theory that focuses on the interplay between the evolution of risk aversion with respect to consumption and the process of development, Robson (1996) examines the evolutionary optimal risk preferences with respect to offspring, and finds that risk neutrality with respect to children is evolutionary optimal in a static environment characterized by idiosyncratic uncertainty. Bernardo and Welch (2001) establish that overconfident entrepreneurs are evolutionary optimal in an environment characterized by poor aggregation of information and herding behavior. Overconfident entrepreneurs provide a positive information externality to the group they belong to by revealing their own information. Palacios and Santos (2004) examine the effect of market incompleteness on the formation of risk aversion, demonstrating that if the formation of lower risk aversion is costly market completeness and greater risk aversion are complements.

${ }^{17}$ The documented higher fertility rates of the countryside over the urban population in medieval Europe (LiviBacci (1997)) does not imply the risk aversion is lower among the rural population. Clearly, the economic role and the cost of child rearing differs across these sectors. The prediction of the theory is that within each sector as long as relative prices are in favor of child rearing the more entrepreneurial individuals have the evolutionary advantage.
} 
of these traits in light of the proposed theory.

Several models in psychiatry and social psychology have been proposed for classifying temperament and personality characteristics. Cloninger (1987) propose four genetically homogeneous and independent dimensions of personality: novelty seeking, harm avoidance, reward dependence and persistence that are hypothesized to be based on distinct neurochemical and genetic substrates. The first two of these traits are closely associated with the notion of risk aversion and entrepreneurial spirit in the economics literature. As elaborated by Kose (2003), "Individuals exhibiting high novelty seeking are enthusiastic, curious, and are quick to engage with whatever is new and unfamiliar, which leads to exploration of potential rewards. Furthermore, they get excited about new ideas and activities easily, for they tend to seek thrills, excitement, and adventures thus they may be described as unconventional or innovative. On the other hand individuals characterized by decreased novelty seeking do not derive special satisfaction from exploration and consequently are contended with or prefer familiar places, people, and situations. Such individuals are resistant or slow to engage in new ideas and activities and thus tend to stick with familiar "tried and true" routines even if there are new and better ways to do the same thing". Harm avoidance is a trait also related to risk aversion. More specifically one of the dimensions that it measures is how an individual reacts to uncertainty. Those who exhibit high harm avoidance rarely take any risks and have difficulty adapting to changes in routine (Kloninger 1987).

Human personality traits that can be reliably measured by rating scales show a considerable heritable component. One such rating scale is the Tridimensional Personality Questionnaire (TPQ), which was designed by Cloninger et al. (1993) to measure Harm Avoidance, Novelty Seeking and Reward Dependence. Several studies have shown that a large component of the observed variation in the behavioral traits as measured by the TPQ can be attributed to genetic differences. For example, genetic analysis of data from 2,680 adult Australian homozygotic and heterozygotic twin pairs demonstrated significant genetic contributions to variation in scores on the Harm Avoidance, Novelty Seeking, and Reward Dependence scales of Cloninger's Tridimensional Personality Questionnaire, accounting for between 54\% and $61 \%$ of the variation in these traits (Heath et al. (1994); Stallings et al (1996)). Similar evidence for genetic heritability of the trait of harm avoidance is provided by Tellengen et al. (1988) who studied personality similarities in twins reared apart and together and concluded that $55 \%$ of the observed differences is due to genetic influences.

Evidence from twin studies strongly suggests that a substantial component of the ob- 
served variation in degrees of novelty seeking may be attributed to genetic variation. (Rodger et al. (2001), and Kohler et al. (1999). Furthermore, the dopamine receptor D4 (DRD4) gene has been studied extensively in the biological literature as a potential candidate for moderating the novelty seeking behavior. Although the evidence is still inconclusive a positive association between a certain polymorphism in the DRD4, the 7-repeat allele, and novelty seeking behavior is most widely documented. The available genetic, biochemical and physiological data suggest that the 7-repeat allele has been subjected to positive selection. This finding implies that once more risk tolerant individuals were introduced in the human population they started procreating at higher rates throughout most of human history, corroborating the focal prediction of the theory.

Cloninger et al. (1993) proposed that individual variations in the novelty seeking trait are mediated by genetic variability in dopamine transmission. Ebstein et al. (1996) tested this hypothesis in a group of 124 unrelated Israeli subjects and found that higher than average novelty seeking test scores were positively and significantly associated with a particular exonic polymorphism, the 7-repeat allele at the locus for the dopamine receptor D4 (DRD4) gene. The association of high novelty seeking and the 7-repeat allele was independent of ethnicity, sex, or age of the subjects. ${ }^{18}$ However, not all subsequent studies have been able to reproduce this association. Shinka et al (2002) conducted a meta-analysis of the published studies regarding the relationship between dopamine receptor D4 gene and novelty seeking and found that the existing evidence is inconclusive for the association between the 7-repeat allele and novelty seeking behavior, noting however that a small positive effect was found for long repeats of the same polymorphism (including the $7 \mathrm{R}$ allele) and novelty seeking.

As to the genetic evolution of the dopamine receptor D4 locus, Ding et al (2002) studying a world wide population sample propose that the $7 \mathrm{R}$ allele originated as a rare mutational event around 40,000 years ago that nevertheless increased to high frequency in human populations by positive selection. To the extent that the 7-repeat allele is associated with novelty seeking behavior the findings of Ding et al (2002) confirm the basic prediction of our model. Risk tolerant individuals at low levels of economic development have the evolutionary advantage and the introduction of more risk tolerant individuals in an environment characterized by very low income levels - the emergence of the 7-repeat allele bearers around 40.000 years ago should have led to an appreciable increase in their representation in the population something that has indeed occurred.

\footnotetext{
${ }^{18}$ These results were corroborated by Benjamin et al. (1996) who investigated the relationship between DRD4 exon 3 sequence variants and personality test scores.
} 
Finally, complementary evidence suggests that risk aversion is indeed hereditary. White et al (2005) examine empirically how entrepreneurial activity is associated with a heritable biological trait, that of testosterone levels. After collecting testosterone and biographical data on experienced MBA students with significant prior involvement in the creation of a new venture and other student subjects with no new venture start-up experience, they find that higher testosterone levels are significantly associated with prior new venture start-up experience. Increased testosterone levels increase the probability of entrepreneurial activity both directly and indirectly via the propensity towards risk. This finding coupled with studies from endocrinology (Meikle, Stringham et al (1988), Harris et al (1998)), which show that production of testosterone levels is heritable, substantiate the assumption regarding the genetic heritability of risk aversion. ${ }^{19}$

\section{The Basic Structure of the Model}

Consider an overlapping-generations economy in which economic activity extends over infinite discrete time. In every period the economy produces a single homogeneous good using land and labor as inputs in the production process. The supply of land is exogenous and fixed over time whereas the supply of labor is determined by the size of the population.

\subsection{Production of Final Output}

Production occurs according to a constant-returns-to-scale technology that is subject to endogenous technological progress. The output produced at time $t, Y_{t}$, is

$$
Y_{t}=\left(A_{t} X\right)^{\alpha} L_{t}^{1-\alpha} ; \quad \alpha \in(0,1)
$$

where $L_{t}$ is the labor employed in period $t, X$ is the land used in production in every period, $A_{t}$ is the technological level in period $t$, and $A_{t} X$ is therefore the "effective resources" used in production in period $t$.

Suppose that there are no property rights over land. ${ }^{20}$ The return to land in every period

\footnotetext{
${ }^{19}$ Nielsen et al. (2005) find that within the group of genes that shows the strongest evidence for positive selection in humans there are also genes that are involved in spermatogenesis that directly influence the Testosterone levels.

${ }^{20}$ The modeling of the production side is based upon two simplifying assumptions. First, capital is not an input in the production function, and second the return to land is zero. Alternatively it could have been assumed that the economy is small and open to a world capital market in which the interest rate is constant. In this case, the quantity of capital will equalize its marginal product to the interest rate, while the price of land will follow a path such that the total return on land (rent plus net price appreciation) will be equal to the interest rate. Allowing for capital accumulation and property rights over land would complicate the model to the point of intractability, but would not affect the qualitative results.
} 
is therefore zero, and the wage rate in period $t$ is equal to the output per worker produced at time $t, y_{t}$.

$$
y_{t}=\left[\left(A_{t} X\right) / L_{t}\right]^{\alpha}
$$

where $\left(A_{t} X\right) / L_{t}$ is the level of effective resources per worker at time $t$.

\subsection{Preferences and Constraints}

In every period $t$, a generation that consists of $L_{t}$ heterogenous individuals joins the labor force. Each individual has a single parent. Members of generation $t$ (those who join the labor force in period $t$ ) live for two periods. In the first period of life (childhood), individuals consume a fraction of their parental income. In the second period of life (parenthood), every individual $i$ of generation $t$ is endowed with 1 unit of time, they work and generate an an income $y_{t}$, which they allocate between consumption, $c_{t}^{i}$ and child rearing $\tau y_{t} n_{t}^{i}$, where $\tau$ is the fraction of parental income that is devoted for raising a child, and $n_{t}^{i}$ is the number of children. ${ }^{21}$

Every generation $t$ consists of individuals that are distinguished by the their degree of risk aversion with respect to consumption which is transmitted formed genetically or culturally. Preferences are transmitted without alteration from generation to generation within a dynasty. The distribution of types evolves over time due to the effect of natural selection on the relative size of each dynasty. In a given environment, the type with the evolutionary advantage (i.e., the type characterized by higher fertility rates) will gradually dominate the population. However, changes in the economic environment may shift the evolutionary advantage to other types.

Preferences of individual $i$ of generation $t$ are represented by a utility function defined over consumption, $c_{t}^{i}$, as well as over the number of their children, $n_{t}^{i}$, ${ }^{22}$ and they are subjected to a subsistence consumption constraint, $\tilde{c}{ }^{23}$ In particular, to simplify the exposition it is assumed

\footnotetext{
${ }^{21}$ The parameter $\tau$ can be interpreted therefore as the time cost of raising a child.

${ }^{22}$ For simplicity, the analysis abstracts from child mortality risk. Alternatively one can interpret the preferences such that parents derive utility from the expected number of surviving offspring and the cost of child rearing is associated only with surviving children.

${ }^{23}$ The utility function could have been defined over consumption above subsistence rather than over a consumption set that is truncated from below by the subsistence consumption constraint. In particular, if $u_{t}^{i}=\left[1 /\left(1-\theta_{i}\right)\right]\left(c_{t}-\tilde{c}\right)^{\left(1-\theta_{i}\right)}+\gamma n_{t}$, then the complexity of the dynamical system would be greatly enhanced. The income expansion path would be smooth, evolving continuously from being nearly vertical for low levels of potential income to asymptotically horizontal for high levels of potential income. Such a utility function by construction displays decreasing relative risk aversion. Hence, dynasties are characterized by declining risk aversion over the process of development. The qualitative results regarding the non-monotonic evolution of reproductive success across such dynasties remain intact. The implications about the convergence process, however, would be partially mitigated because although in advanced stages of development dynasties of relatively risk averse individuals have the evolutionary advantage the higher income alleviates their reduced risk tolerance.
} 
that $\tau \leq \tilde{c}<(1-\tau) .{ }^{24}$ The utility function of a individual of type $i$ of generation $t$ is

$$
u_{t}^{i}=\frac{\left(c_{t}^{i}\right)^{1-\theta_{i}}}{1-\theta_{i}}+\gamma n_{t}^{i} ; \quad \gamma>1, \quad \theta_{i} \in(1, \bar{\theta})
$$

where $\theta_{i}$ is the parameter of risk aversion, $\theta_{i} \in(1, \bar{\theta})$, where $\bar{\theta} \equiv 1+\ln (\tau / \gamma) / \ln \tilde{c}$. The higher is $\theta_{i}$, the more risk averse is individual $i$. The degree of risk aversion is the only source of heterogeneity within a generation. ${ }^{25}$ Risk aversion is assumed to be perfectly hereditary, and the distribution of $\theta_{i}$ changes therefore due to the effect of natural selection on the distribution of types.

Remark: The qualitative results will not be affected if a broader class of preferences is adopted. In particular, as established in Section 6, the qualitative results will be maintained if:

(a) Individuals are risk averse with respect to fertility (regardless of whether the degree of risk aversion with respect to fertility is larger or smaller than the degree of risk aversion with respect to consumption.

(b) The degree of risk aversion is distributed over the interval $(0, \infty)$. (i.e., $\left.\theta_{i} \in(0, \infty)\right)$.

(c) Risk-seeking behavior (i.e., $\theta_{i}<0$ ) was present in the population in the distant past.

(d) There exists variations among individuals in the risk attitude towards children.

(e) Individuals bear children due to their concern for old-age support.

Individuals allocate their wage income, $y_{t}$, between consumption, $c_{t}^{i}$, and expenditure on child rearing, $y_{t} \tau n_{t}^{i}$. The individual's budget constraint is therefore

$$
y_{t} \tau n_{t}^{i}+c_{t}^{i} \leq y_{t}
$$

\subsection{Optimization}

Members of generation $t$ choose the number of their children, and therefore their own consumption, so as to maximize their utility function subject to their budget and the subsistence

\footnotetext{
${ }^{24}$ As it will become apparent, given the evolution of the relative price of consumption with respect to children, this is a realistic and necessary assumption which implies that the cost of physiologically sustaining an adult, $\tilde{c}$, does not exceed the level beyond which relative prices are in favor of consumption. Specifically, at early stages of development, when wage income is sufficiently low (i.e., $y_{t}<1 / \tau$ ) the cost of raising a child, $y_{t} \tau$, is lower than the cost of a consumption unit whose price is normalized to 1 . It is at this stage that more entrepreneurial individuals allocate more resources to the relatively cheaper good, i.e. children, and have the evolutionary advantage. As the economy develops and wage income increases, however, the cost of raising a child increases proportionally with income, whereas the cost per unit of consumption decreases with income. Thus, at sufficiently mature stages of development (i.e., $y_{t}>1 / \tau$ ) the more entrepreneurial type favors the consumption good.

${ }^{25}$ For simplicity, it is assumed that the subsistence consumption constraint and the weight given to consumption in the utility function are homogenous across individuals and hence they are not subjected to natural selection.
} 
consumption constraints. Substituting (4) into (3), the optimization problem of a member $i$ of generation $t$ is:

$$
n_{t}^{i}=\operatorname{argmax}\left\{\frac{\left[y_{t}\left(1-n_{t}^{i} \tau\right)\right]^{\left(1-\theta_{i}\right)}}{\left(1-\theta_{i}\right)}+\gamma n_{t}^{i}\right\}
$$

Subject to:

$$
\begin{aligned}
& c_{t}^{i}=y_{t}\left(1-n_{t}^{i} \tau\right) \geq \tilde{c} ; \\
& n_{t}^{i} \geq 0 .
\end{aligned}
$$

As long as the potential wage income at time $t$ is sufficiently high so as to assure that the optimal level of consumption exceeds the subsistence consumption constraint $\tilde{c}$ (i.e., as long as $y_{t}$ is above the level at which the subsistence constraint is binding), and as long as the non-negative fertility constraint does not bind, it follows from the individual optimization that the consumption of individual $i$ in period $t$ is $c_{t}^{i}=\left[\tau y_{t} / \gamma\right]^{1 / \theta_{i}} \equiv c\left(y_{t} ; \theta_{i}\right)$.

Lemma 1 There exists a threshold level of income, $\tilde{y}^{i}=\tilde{y}\left(\theta_{i}\right) \equiv(\gamma / \tau) \tilde{c}^{\theta_{i}}$, such that the subsistence consumption constraint binds for individual $i$ if and only if $y_{t}<\tilde{y}\left(\theta_{i}\right)$.

$$
\tilde{c}<\tilde{y}\left(\theta_{i}\right)<\gamma / \tau
$$

and it is lower the higher is the degree of risk aversion, i.e.,

$$
\frac{\partial \tilde{y}\left(\theta_{i}\right)}{\partial \theta_{i}}<0
$$

Proof. Since $c\left(y_{t} ; \theta_{i}\right)$ is strictly monotonically increasing in $y_{t}$ and since $c\left(0 ; \theta_{i}\right)=0$ and $\lim _{y_{t}^{i} \rightarrow \infty} c\left(y_{t} ; \theta_{i}\right)=\infty$, it follows from the Intermediate Value Theorem that there exists a unique level of income, $\tilde{y}^{i}$, such that $c\left(\tilde{y}^{i} ; \theta_{i}\right) \equiv\left[\tau \tilde{y}^{i} / \gamma\right]^{1 / \theta_{i}}=\tilde{c}$. Hence, there exists $\tilde{y}^{i}=$ $(\gamma / \tau) \tilde{c}^{\theta_{i}} \equiv \tilde{y}\left(\theta_{i}\right)$ such that if $y_{t}<\tilde{y}\left(\theta_{i}\right)$ then $c\left(y_{t} ; \theta_{i}\right)<\tilde{c}$ and the subsistence consumption constraint binds, whereas if $y_{t} \geq \tilde{y}\left(\theta_{i}\right)$ then $c\left(y_{t} ; \theta_{i}\right) \geq \tilde{c}$ and the subsistence consumption constraint does not bind. Moreover, since $\tilde{c}<1$, and $(\gamma / \tau)>1$, it follows that $\tilde{y}\left(\theta_{i}\right) \equiv$ $(\gamma / \tau) \tilde{c}^{\theta_{i}}>\tilde{c}$ and $\partial \tilde{y} / \partial \theta_{i}=(\gamma / \tau) \tilde{c}^{\theta_{i}} \ln \tilde{c}<0$.

Corollary 1 There exists a threshold level of risk aversion, $\tilde{\theta}\left(y_{t}\right) \equiv \ln \left(\tau y_{t} / \gamma\right) / \ln \tilde{c}$, such that the subsistence consumption constraint binds for individual $i$ if and only if $\theta_{i}<\tilde{\theta}\left(y_{t}\right)$, where

$$
\tilde{\theta}\left(y_{t}\right) \geq 0 \quad \text { if and only if } \quad y_{t} \leq \gamma / \tau \text {. }
$$

The threshold level of risk aversion $\tilde{\theta}\left(y_{t}\right)$ decreases with the level of income, i.e.,

$$
\frac{\partial \tilde{\theta}\left(y_{t}\right)}{\partial y_{t}}<0
$$


Proof. As established in Lemma 1, the subsistence consumption constraint binds for individual $i$ if and only if $y_{t}<\tilde{y}\left(\theta_{i}\right)=(\gamma / \tau) \tilde{c}^{\theta_{i}}$. Since $\tilde{y}\left(\theta_{i}\right)$ is strictly monotonically decreasing in $\theta_{i}$, it is invertible, $\theta_{i} \equiv \ln \left(\tau \tilde{y}^{i} / \gamma\right) / \ln \tilde{c}$, and the subsistence consumption constraint binds for individual $i$ if and only if $\theta_{i}<\tilde{\theta}\left(y_{t}\right) \equiv \ln \frac{\tau y_{t}}{\gamma} / \ln \tilde{c}$. Since $\ln \tilde{c}<0$, it follows that $\tilde{\theta}\left(y_{t}\right) \geq 0$ if and only if $\tau y_{t} / \gamma<1$ (and thus $\ln \tau y_{t} / \gamma<0$ ). Moreover, $\partial \tilde{\theta}\left(y_{t}\right) / \partial y_{t}=(\ln \tilde{c}) / y_{t}<0$.

Thus, at sufficiently low levels of income individuals of all types are constrained by the subsistence requirement. However, the subsistence consumption constraint stops binding at a lower level of income for the more risk averse individuals.

At follows from Lemma 1 , as long as $\tilde{c} \leq y_{t} \leq \tilde{y}\left(\theta_{i}\right)$ the subsistence consumption constraint binds, the level of consumption of individual $i$ is equal to the subsistence level, $\tilde{c}$, and given the budget constraint (4), the level of fertility is $\left[1-\left(\tilde{c} / y_{t}\right)\right] / \tau$. Moreover, as follows from the optimization problem (5), if the subsistence consumption constraint is not binding, $c_{t}^{i}=\left[\tau y_{t} / \gamma\right]^{1 / \theta_{i}}$ and therefore $n_{t}^{i}=\left[1-c_{t}^{i} / y_{t}\right] / \tau>0 .{ }^{26}$

The consumption of individual of type $\theta_{i}$ as a function of the income level $y_{t}$ is

$$
c_{t}^{i}=\tilde{c}\left(y_{t} ; \theta_{i}\right) \equiv\left\{\begin{array}{cl}
\tilde{c} & \text { if } \quad \tilde{c} \leq y_{t} \leq \tilde{y}\left(\theta_{i}\right) \\
\left(\tau y_{t} / \gamma\right)^{1 / \theta_{i}} & \text { if } \quad y_{t} \geq \tilde{y}\left(\theta_{i}\right)
\end{array}\right.
$$

where $\partial c_{t}^{i} / \partial y_{t}>0$ for $y_{t} \geq \tilde{y}\left(\theta_{i}\right)$.

The number of children of individual of type $\theta_{i}$ as a function of the income level $y_{t}$ is

$$
n_{t}^{i}=n\left(y_{t} ; \theta_{i}\right) \equiv n^{i}\left(y_{t}\right)= \begin{cases}{\left[1-\left(\tilde{c} / y_{t}\right)\right] / \tau} & \text { if } \quad \tilde{c} \leq y_{t} \leq \tilde{y}\left(\theta_{i}\right) \\ {\left[1-(\tau / \gamma)^{1 / \theta_{i}} y_{t}^{\left(1-\theta_{i}\right) / \theta_{i}}\right] / \tau} & \text { if } \quad y_{t} \geq \tilde{y}\left(\theta_{i}\right)\end{cases}
$$

The effect of an increase in income, $y_{t}$, on the individual's allocation of resources between

\footnotetext{
${ }^{26}$ The positivity follows from the fact that $c_{t}^{i}<y_{t}$.
} 
child rearing and consumption is depicted in Figure 1.

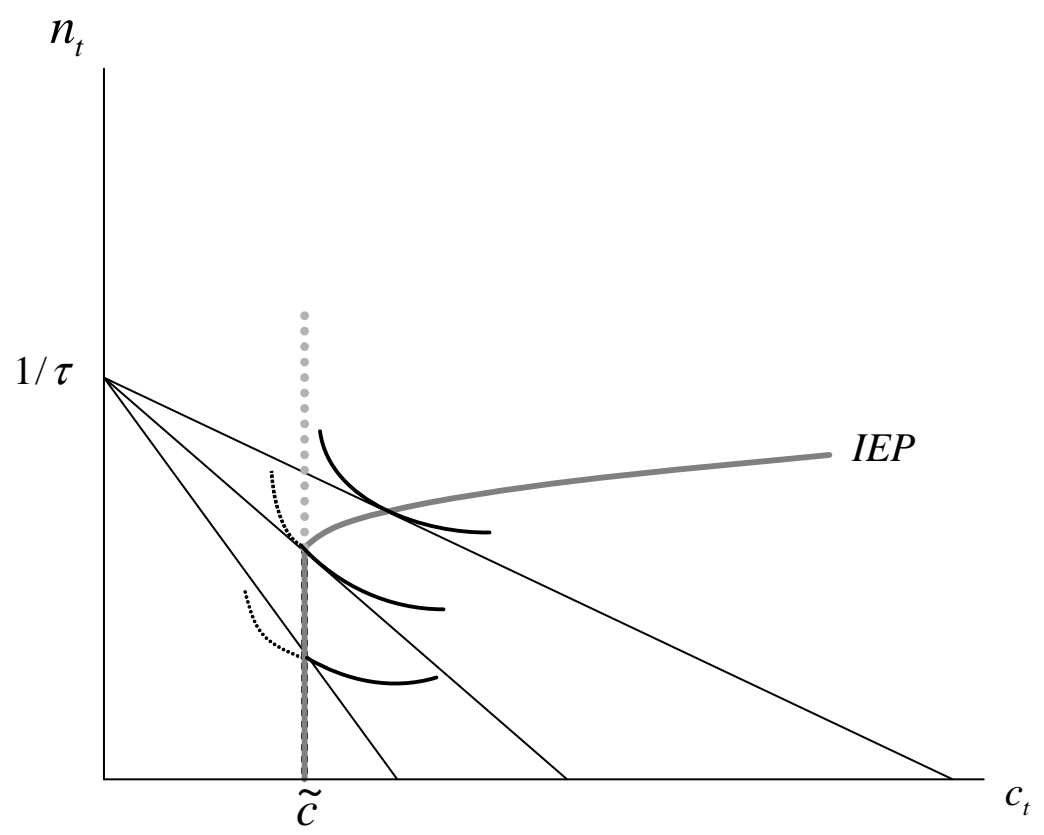

Figure 1. The Income Expansion Path of Individual $i$ :

The Optimal Levels of Consumption and Fertility as a Function of Income

The income expansion path is vertical as long as the subsistence consumption constraint is binding. As income increases, the individual can obtain the subsistence consumption with a smaller fraction of income and the fraction of income devoted to child rearing increases. Once, the level of income is sufficiently high such that the subsistence constraint is not binding, the income expansion path has a positive but finite slope, reflecting increasing allocation of resources for both consumption and child rearing.

As depicted in Figure 2, for $y_{t}>\tilde{c}$, the fertility rate of individual $i$ in any period $t, n_{t}^{i}$, is a positive, increasing, strictly concave function of $y_{t}$. In particular, $n_{t}^{i}>0$ for all $y_{t}>\tilde{c}$,

$$
\frac{\partial n_{t}^{i}}{\partial y_{t}}= \begin{cases}\tilde{c} /\left(\tau y_{t}^{2}\right)>0 & \text { if } \quad \tilde{c} \leq y_{t} \leq \tilde{y}\left(\theta_{i}\right) \\ {\left[\left(\theta_{i}-1\right)(\tau / \gamma)^{1 / \theta_{i}} y_{t}^{\left(1-2 \theta_{i}\right) / \theta_{i}}\right] / \theta_{i} \tau>0} & \text { if } \quad y_{t} \geq \tilde{y}\left(\theta_{i}\right)\end{cases}
$$

and

$$
\frac{\partial^{2} n_{t}^{i}}{\partial^{2} y_{t}}<0 \quad \text { if } \quad y_{t}>\tilde{c}
$$




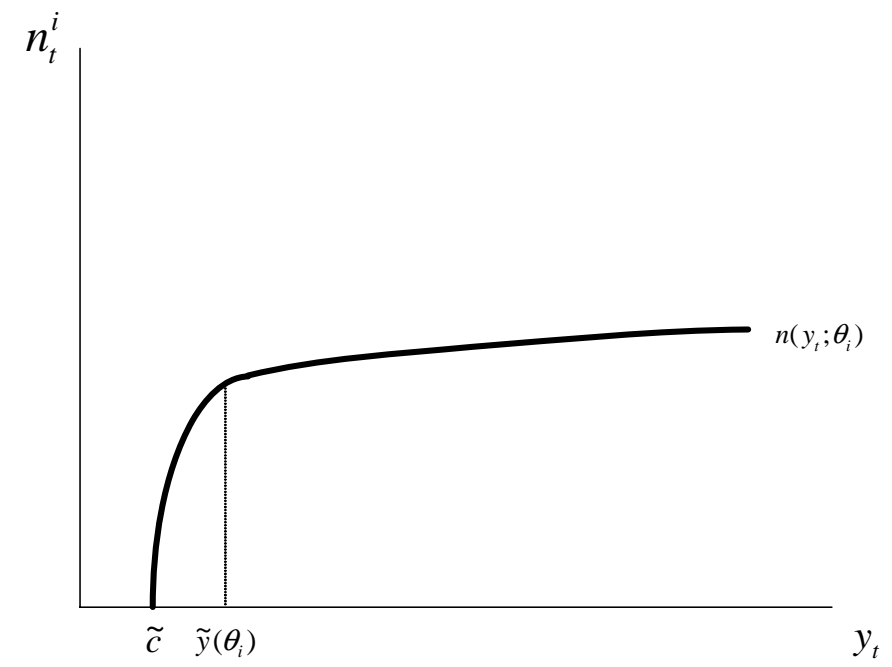

Figure 2. Fertility of Individual $i$ as a Function of Income.

Moreover, as established in the following lemma, as long as the subsistence consumption constraint binds, the fertility rate exceeds the replacement level if income per worker is not smaller than $\tilde{c} /(1-\tau)$.

Lemma 2 1. If the subsistence consumption constraint binds for individual $i$ in period $t$, (i.e., if $\left.y_{t} \leq \tilde{y}\left(\theta_{i}\right)\right)$ then the individual's fertility rate is above replacement if $y_{t} \geq \tilde{c} /(1-\tau)$, i.e.,

$$
n_{t}^{i}=n^{i}\left(y_{t}\right) \geq 1 \quad \text { if } \quad \tilde{c} /(1-\tau) \leq y_{t} \leq \tilde{y}\left(\theta_{i}\right)
$$

2. Fertility is above replacement for all individuals if income per capita exceeds $\gamma / \tau$, i.e.,

$$
n^{i}\left(y_{t}\right)>1 \quad \text { if } \quad y_{t} \geq \gamma / \tau
$$

Proof. See Appendix.

\subsection{Risk Aversion and Reproductive Success}

The effect of risk aversion on fertility rate and thus on reproductive success, as depicted in Figure 3, evolves non-monotonically in the process of development. At early stages of development, when the level of income is low, higher degree of risk aversion has an adverse effect on fertility and reproductive success, whereas at higher levels of income, higher degree of risk aversion has a beneficial effect on reproductive success. This non monotonic effect of risk aversion 
on fertility across different levels of output per capita is the driving force behind the changing distribution of the risk aversion in the population along the path of the economic development.

Proposition 1 The effect of risk aversion on reproductive success evolves non-monotonically in the process of development

$$
\frac{\partial n_{t}^{i}}{\partial \theta_{i}}\left\{\begin{array}{lll}
=0 & \text { if } & \tilde{c}<y_{t}<\gamma / \tau \text { and } \theta_{i} \leq \tilde{\theta}\left(y_{t}\right) \equiv \ln \frac{\tau y_{t}}{\gamma} / \ln \tilde{c} \\
<0 & \text { if } & \tilde{c}<y_{t}<\gamma / \tau \text { and } \theta_{i}>\tilde{\theta}\left(y_{t}\right) \equiv \ln \frac{\tau y_{t}}{\gamma} / \ln \tilde{c} \\
=0 & \text { if } \quad y_{t}=\gamma / \tau \\
>0 & \text { if } \quad y_{t}>\gamma / \tau
\end{array}\right.
$$

Proof. As follows from (7)

$$
\frac{\partial n_{t}^{i}}{\partial \theta_{i}}=\left\{\begin{array}{ccc}
0 & \text { if } & \tilde{c}<y_{t}<\tilde{y}\left(\theta_{i}\right) \\
\frac{\left(\tau y_{t} / \gamma\right)^{1 / \theta_{i} \ln \left(\tau y_{t} / \gamma\right)}}{\theta_{i}^{2} \tau y_{t}} & \text { if } & y_{t} \geq \tilde{y}\left(\theta_{i}\right)
\end{array}\right.
$$

Hence: (a) Since $\left\{\left[\tilde{c}<y_{t}<\tilde{y}\left(\theta_{i}\right)\right]\right.$ if and only if $\left[\tilde{c}<y_{t}<\gamma / \tau\right]$ and $\left.\left[\theta_{i}<\tilde{\theta}\left(y_{t}\right) \equiv \ln \left(\tau y_{t} / \gamma\right) / \ln \tilde{c}\right]\right\}$, it follows from (7) that $\partial n_{t}^{i} / \partial \theta_{i}=0$ if $\left[\tilde{c}<y_{t}<\gamma / \tau\right.$ and $\left.\theta_{i} \leq \ln \frac{\tau y_{t}}{\gamma} / \ln \tilde{c}\right]$. (b) Since $\left\{\left[y_{t}>\tilde{y}\left(\theta_{i}\right)\right]\right.$ if and only if $\left.\left[\theta_{i}>\tilde{\theta}\left(y_{t}\right) \equiv \ln \left(\tau y_{t} / \gamma\right) / \ln \tilde{c}\right]\right\}$, it follows from (7) that $\partial n_{t}^{i} / \partial \theta_{i}<0$ if $\left[\tilde{c}<y_{t}<\gamma / \tau\right.$ and $\left.\theta_{i}>\ln \frac{\tau y_{t}}{\gamma} / \ln \tilde{c}\right]$, noting that $\ln \left(\tau y_{t} / \gamma\right)<0$ if and only if $\left[y_{t}<\gamma / \tau\right]$. (c) Since $\ln \left(\tau y_{t} / \gamma\right)=0$ if and only if $\left[y_{t}=\gamma / \tau\right]$, it follows from (7) that $\partial n_{t}^{i} / \partial \theta_{i}=0$ if $y_{t}=\gamma / \tau$. (d) Since $\ln \left(\tau y_{t} / \gamma\right)>0$ and if and only if $\left[y_{t}>\gamma / \tau\right]$, it follows from (7) that $\partial n_{t}^{i} / \partial \theta_{i}>0$ if $y_{t}>\gamma / \tau$.

Hence, for low levels of income $\tilde{c}<y_{t}<\gamma / \tau$, individuals with a lower degree of risk aversion have an evolutionary advantage, whereas for high levels of income $y_{t}>\gamma / \tau$, individuals with a higher degree of risk aversion gain the evolutionary advantage.

At low levels of income, i.e., $\tilde{c} \leq y_{t}<\gamma / \tau$, the subsistence consumption constraint binds all individuals whose $\theta_{i} \leq \ln \left(\tau y_{t} / \gamma\right) / \ln \tilde{c}$. The entire resources that remain after subsistence consumption are devoted to fertility and risk aversion therefore has no effect on fertility. However, the more risk averse individuals, whose $\theta_{i}>\ln \left(\tau y_{t} / \gamma\right) / \ln \tilde{c}$ are not constrained by the subsistence consumption constraints. They do not allocate the entire resources above subsistence to fertility. Hence, as long as $y_{t}<\gamma / \tau$ the marginal effect of higher $\theta$ on fertility is negative .

At higher levels of income, i.e., $y_{t} \geq \gamma / \tau$, the subsistence consumption constraint is not binding for any individual regardless of the degree of risk aversion. Since the marginal utility from consumption, for any given level of income above $\gamma / \tau$, is lower the higher is the degree of 
risk aversion, fertility is higher the higher is the degree of risk aversion and the high risk averse type has an evolutionary advantage.
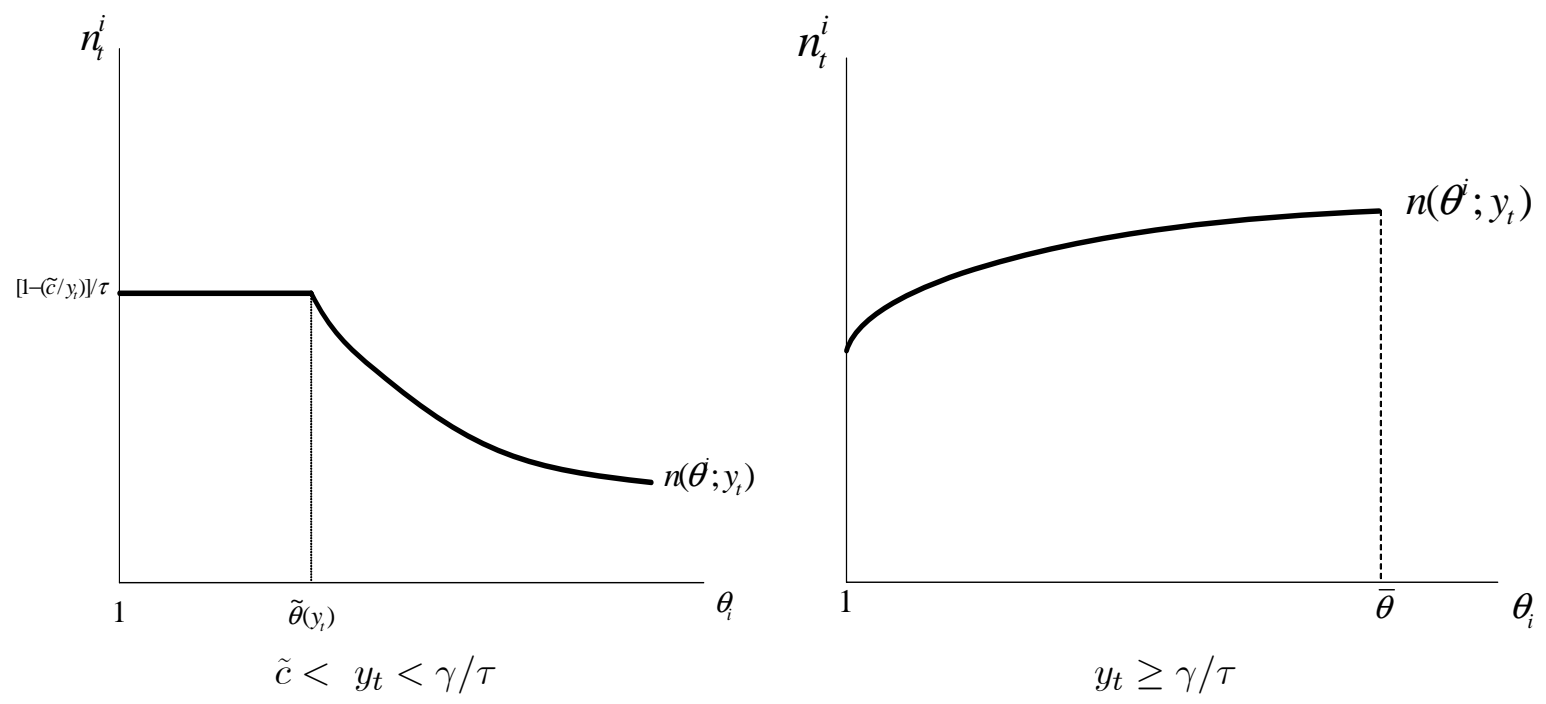

Figure 3. Risk Aversion and Reproductive Success $\theta_{i} \in(1, \bar{\theta})$

\section{The Process of Development}

The process of development is governed by the time path of the level of technology, income per capita and the composition of the risk aversion traits.

\subsection{The Evolution in the Composition of Types}

Suppose that at time 0 the economy consists of $L_{0}$ individuals of two types: type 1 and type 2 , Individuals are distinguished by their degree of risk aversion. Individuals of type 1 are less risk averse than individuals of type 2, i.e., $1<\theta_{1}<\theta_{2}<\bar{\theta}$, and $\beta_{o}$ is the fraction of the less risk averse (type 1) individuals in the population.

The two types of individuals supply inelastically one unit of labor, regardless of their degree of risk aversion, and generate therefore the same level of income. However, as established in (6), (7) and Proposition 1, the degree of risk aversion affects their consumption and fertility decisions, and therefore their reproductive success.

In accordance with the historical pattern of fertility, income per worker is assumed to be sufficiently high in every period, so as to assure that fertility rates are at least at replacement level in period 0 for individuals for which the subsistence consumption constraint binds. Hence 
in light of Lemma 2, it is assumed that income per-capita in period 0 is set to be equal to $\tilde{c} /(1-\tau)$, i.e., $y_{0}=\tilde{c} /(1-\tau)$.

As follows from Lemma 1 the subsistence consumption constraint stops binding earlier for individuals of type 2, i.e., $\tilde{y}\left(\theta_{2}\right)<\tilde{y}\left(\theta_{1}\right)$. As long as the subsistence consumption constraint binds for both types, it follows from Proposition 1 that risk aversion has no effect on fertility and the composition of types in the population does not change.

However, as income increases, the subsistence consumption constraint stops binding for the high risk-averse individuals (type 2) and ultimately for individuals of (type 1), and as established in Proposition 1, the forces of natural selection affect the composition of types and the economic environment.

Hence, without loss of generality, suppose that at time 0 the level of income is such that the subsistence consumption constraint does not bind for individuals of type 2, while it still binds for individuals of type 1 . Since $y_{0}=\tilde{c} /(1-\tau)$, it follows that the subsistence constraint does not bind for the high risk averse (type 2) individuals if $\tilde{y}\left(\theta_{2}\right)<\tilde{c} /(1-\tau)$, whereas for the less risk averse the subsistence consumption constraint still binds if $\tilde{y}\left(\theta_{1}\right)>\tilde{c} /(1-\tau)$. Thus, ${ }^{27}$

$$
\tilde{c}<\tilde{y}\left(\theta_{2}\right)<\tilde{c} /(1-\tau)<\tilde{y}\left(\theta_{1}\right)
$$

Alternatively, since $\theta_{i} \in(1, \bar{\theta})$, it is assumed that ${ }^{28}$

$$
1<\theta_{1}<\tilde{\theta}(\tilde{c} /(1-\tau))<\theta_{2}<\bar{\theta}
$$

where as defined in Corollary $1 \tilde{\theta}(\tilde{c} /(1-\tau))$ is $\tilde{\theta}\left(y_{t}\right) \equiv \ln \left(\tau y_{t} / \gamma\right) / \ln \tilde{c}$, evaluated at $y_{t}=$ $\tilde{c} /(1-\tau)$.

Corollary 2 If $1<\theta_{1}<\tilde{\theta}(\tilde{c} /(1-\tau))<\theta_{2}$, then

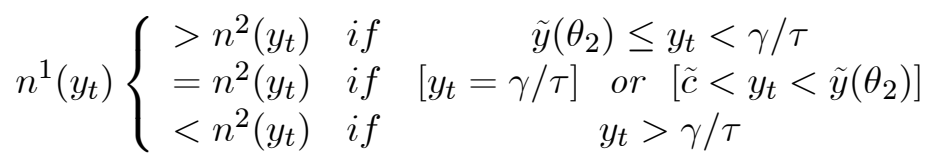

Proof. The corollary follows directly from (7) and Proposition 1, noting that since $\theta_{2}>$ $\tilde{\theta}(\tilde{c} /(1-\tau)) \equiv 1+\ln (\tau /(\gamma(1-\tau))) / \ln \tilde{c}$ then $\theta_{2}>\ln \frac{\tau y_{t}}{\gamma} / \ln \tilde{c}$ for $\tilde{y}\left(\theta_{2}\right) \leq y_{t}<\gamma / \tau$.

\footnotetext{
${ }^{27}$ It should be noted that since $\tilde{y}\left(\theta_{2}\right) \equiv(\gamma / \tau) \tilde{c}^{\theta_{2}}$, and since $\theta_{2}<\bar{\theta} \equiv 1+\ln (\tau / \gamma) / \ln \tilde{c}$, it is necessarily the case that $\tilde{c}<\tilde{y}\left(\theta_{2}\right)$.

${ }^{28} \tilde{\theta}(1)>1$ if and only if $\tilde{c}>\tau / \gamma$. Hence, since $\tilde{c} \geq \tau$ and $\gamma>1$, it follows that $\tilde{c}>\tau / \gamma$ and therefore $\tilde{\theta}(1)>1$.
} 
Hence, as depicted in Figure 4, in early stages of development, when the subsistence consumption constraint binds for some individuals, (i.e., $\left.\tilde{c} /(1-\tau) \leq y_{t}<\gamma / \tau\right)$, the risktolerant individuals (type 1) have an evolutionary advantage, whereas as soon as the economy escapes from the Malthusian trap and the subsistence consumption constraints is no longer binding (i.e., $y_{t}>\gamma / \tau$ ), the risk averse individuals (type 2) have an evolutionary advantage. ${ }^{29}$

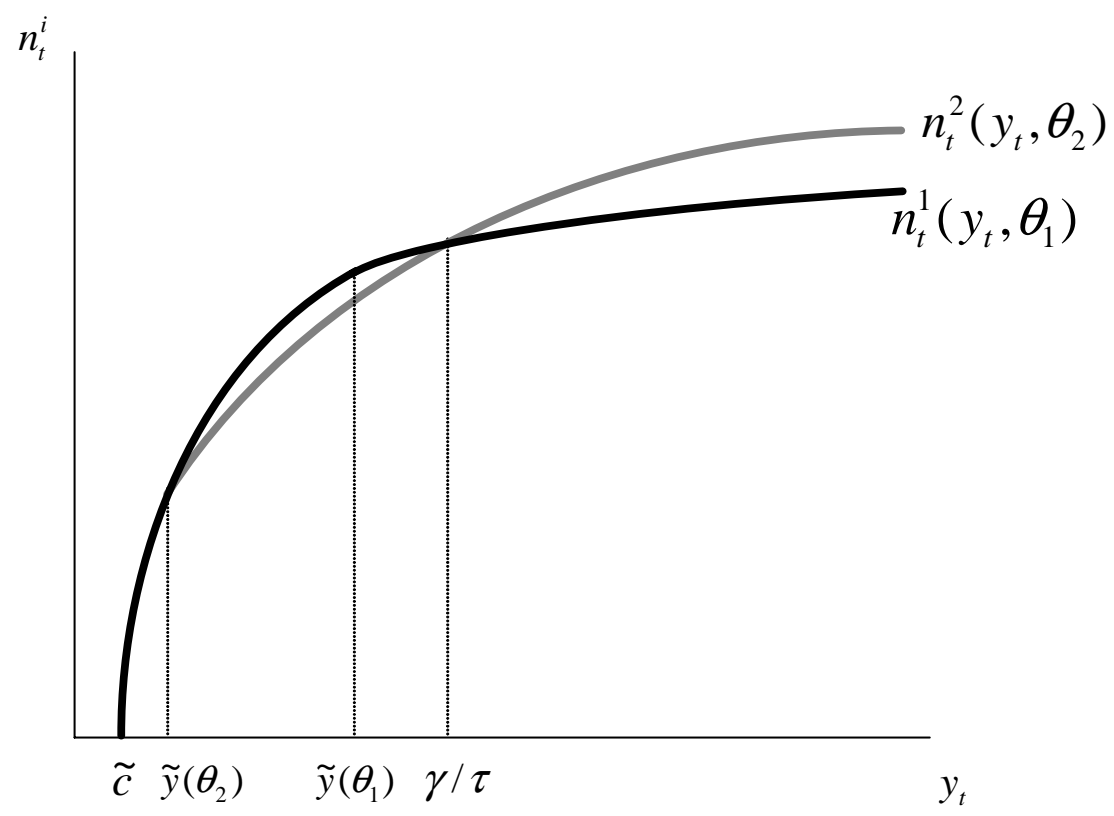

Figure 4. Reversal in the Evolutionary Advantage in the Process of Development

$$
\tilde{c}<\tilde{y}\left(\theta_{2}\right)<\tilde{c} /(1-\tau)<\tilde{y}\left(\theta_{1}\right)
$$

Given the size of the population in period $t, L_{t}$, the size of the population in period $t+1$, $L_{t+1}$, is therefore

$$
L_{t+1}=n_{t}^{1} \beta_{t} L_{t}+n_{t}^{2}\left(1-\beta_{t}\right) L_{t}
$$

where $\beta_{t}$ is the fraction of the risk-tolerant individuals (type 1 ) in the population, and $n_{t}^{i}$ is the number of offspring born to individual of type $i$ in period $t$.

The fraction of individuals of type 1 in the population in period $t+1, \beta_{t+1}$, is therefore

\footnotetext{
${ }^{29}$ Unlike Galor and Moav (2002) in which differences in preferences (i.e., attitude towards child quality) generates differences in income and which results in differences in reproductive success, in the proposed theory the evolutionary advantage is based upon differences in preferences (i.e., attitude towards risk) that do not affect income, but nevertheless, generate variations in fertility and thus reproductive success.
} 


$$
\beta_{t+1}=\frac{\beta_{t} n_{t}^{1}}{\beta_{t} n_{t}^{1}+\left(1-\beta_{t}\right) n_{t}^{2}} .
$$

Hence, it follows from (7) that

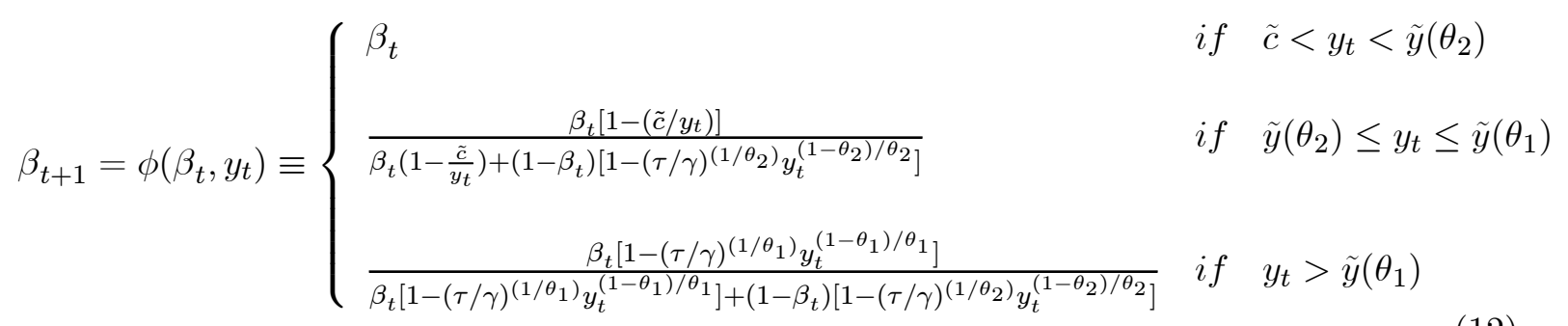

Lemma 3 The Properties of $\phi\left(\beta_{t}, y_{t}\right)$

For $y_{t} \geq \tilde{y}\left(\theta_{2}\right)$,

1. $\phi\left(0, y_{t}\right)=0 \quad$ and $\quad \phi\left(1, y_{t}\right)=1$

2. $\phi_{\beta}\left(\beta_{t}, y_{t}\right)>0$ and $\left[\phi_{\beta \beta}\left(\beta_{t}, y_{t}\right) \gtrless 0\right.$ iff $\left.y_{t} \gtrless \gamma / \tau\right]$

Proof. See Appendix.

Hence, as depicted in Figure 5, for a given level of income per worker, $y_{t}$, the fraction of risk-tolerant individuals in the population increases monotonically over time and approaches 1 , if $\tilde{y}\left(\theta_{2}\right) \leq y_{t} \leq \tilde{y}\left(\theta_{1}\right)$, whereas this fraction declines monotonically over time and approaches 0 , if $y_{t}>\gamma / \tau$. 

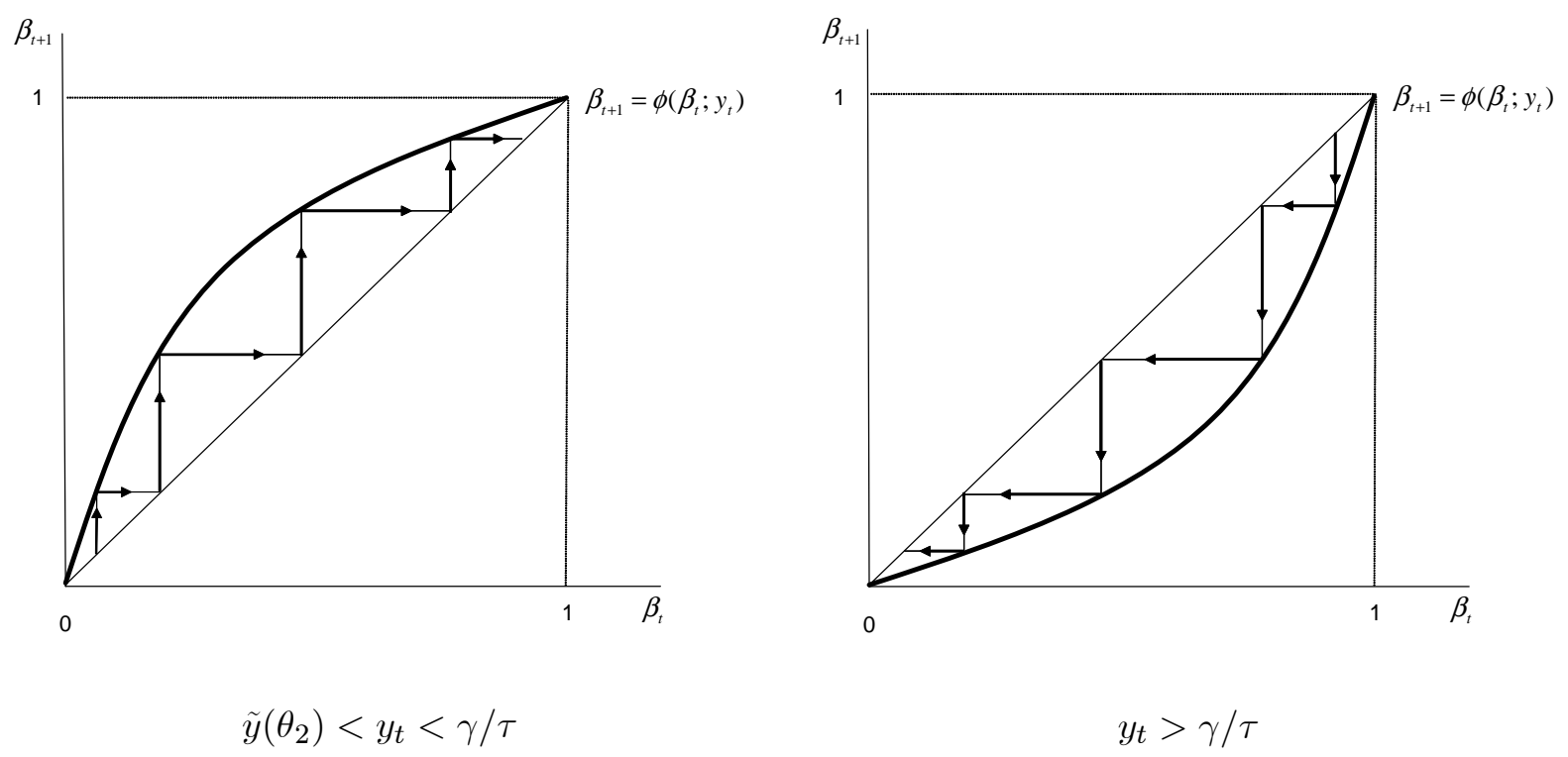

Figure 5. The Evolution of the Proportion of Risk-Tolerant Individuals, $\beta_{t}$, for a given Income Level

\subsection{Technological Progress}

Technological progress, $g_{t+1}$, that takes place between periods $t$ and $t+1$ depends on the fraction of the risk-tolerant individuals within the working generation in period $t, \beta_{t}$, and on the level of income per capita in period $t, y_{t}{ }^{30}$

$$
g_{t+1} \equiv \frac{A_{t+1}-A_{t}}{A_{t}}=g\left(\beta_{t}, y_{t}\right),
$$

where as the rate of technological progress between period $t$ and $t+1$ is a (weakly) positive, (weakly) increasing, concave function of the fraction of risk-tolerant individuals among the

\footnotetext{
${ }^{30}$ While the role of the scale effect in the Malthusian epoch, is essential, none of the existing results depend on the presence or the absence of the scale effect in the modern era. The functional form of technological progress given in (13) can capture both the presence and the absence of the scale effect in the modern era. As discussed in the introduction there is extensive evidence on the role of risk tolerance in innovative activities. The positive role of income per capita in technological progress is well established as well. In a Malthusian environment, a higher level of income per capita will be associated with a larger population that would have a positive effect on the supply, the demand and the diffussion of knowledge. Moreover, it will foster specialization and trade and will therefore enhance technological progress (Kremer (1993) and Galor and Weil (2000). In the industrial world higher income per capita will support a more educated population that is more likely to implement new technologies (Schultz (1975), and will generate a wider tax base that would permit extensive investment in infrastructure, education and research.
} 
working generation at time $t$ and the level of income per-capita (that assure survival and replacement fertility). ${ }^{31}$

$$
\begin{aligned}
g_{y}\left(\beta_{t}, y_{t}\right) \geq 0 \text { and } g_{y y}\left(\beta_{t}, y_{t}\right) \leq 0 & \forall \beta_{t} \in[0,1] \text { and } \forall y_{t}>\tilde{c} \\
g_{\beta}\left(\beta_{t}, y_{t}\right) \geq 0 \text { and } g_{\beta \beta}\left(\beta_{t}, y_{t}\right) \leq 0 & \forall \beta_{t} \in[0,1) \text { and } \forall y_{t}>\tilde{c}
\end{aligned} .
$$

The time path of the level of technology is given therefore by

$$
A_{t+1}=\left(1+g_{t+1}\right) A_{t},
$$

where the level of technology at time 0 is given at a level $A_{0}$.

\subsection{The Time Path of Income Per Worker}

As follows from (2), (10), (13) and (14) income per capita in period $t+1$ is

$$
y_{t+1}=\left(\frac{A_{t+1} X}{L_{t+1}}\right)^{\alpha}=\left(\frac{A_{t} X}{L_{t}}\right)^{\alpha}\left(\frac{\left[1+g\left(\beta_{t}, y_{t}\right)\right]}{\beta_{t} n_{t}^{1}+\left(1-\beta_{t}\right) n_{t}^{2}}\right)^{\alpha} .
$$

Thus,

$$
y_{t+1}=y_{t}\left(\frac{\left[1+g\left(\beta_{t}, y_{t}\right)\right]}{\left.\beta_{t} n_{t}^{1}+\left(1-\beta_{t}\right) n_{t}^{2}\right)}\right)^{\alpha}
$$

Hence, it follows from (14) that the income per capita in period $t+1$ is determined by the level of income per capita in period $t, y_{t}$, and the fraction of risk-tolerant individuals in the adult population, $\beta_{t}$.

$$
y_{t+1}=\psi\left(\beta_{t}, y_{t}\right)
$$

where

$$
\psi\left(\beta_{t}, y_{t}\right) \equiv \begin{cases}y_{t}\left[\frac{\left[1+g\left(\beta_{t}, y_{t}\right)\right]}{\left[1-\left(\tilde{c} / y_{t}\right)\right] / \tau}\right]^{\alpha} & \text { if } \quad \tilde{c}<y_{t}<\tilde{y}\left(\theta_{2}\right) \\ y_{t}\left[\frac{\left[1+g\left(\beta_{t}, y_{t}\right)\right]}{\left\{\beta_{t}\left(1-\tilde{c} / y_{t}\right)+\left(1-\beta_{t}\right)\left[1-(\tau / \gamma)^{1 / \theta_{2}} y_{t}^{\left(1-\theta_{2}\right) / \theta_{2}}\right]\right\} / \tau}\right]^{\alpha} & \text { if } \tilde{y}\left(\theta_{2}\right)<y_{t} \leq \tilde{y}\left(\theta_{1}\right) \\ y_{t}\left[\frac{\left[1+g\left(\beta_{t}, y_{t}\right)\right]}{\left\{\beta_{t}\left[1-(\tau / \gamma)^{1 / \theta_{1}} y_{t}^{\left(1-\theta_{1}\right) / \theta_{1}}\right]+\left(1-\beta_{t}\right)\left[1-(\tau / \gamma)^{1 / \theta_{2}} y_{t}^{\left(1-\theta_{2}\right) / \theta_{2}}\right]\right\} / \tau}\right]^{\alpha} & \text { if } \tilde{y}\left(\theta_{1}\right) \leq y_{t}\end{cases}
$$

\footnotetext{
${ }^{31}$ For a sufficiently low income level and small fraction of risk tolerant in the population the rate of technological progress is strictly positive only every several periods. Furthermore, the number of periods that pass between two episodes of technological improvement declines with an increase in both these factors. These assumptions assure that in early stages of development the economy is in a Malthusian steady-state with zero growth rate of output per capita, but ultimately the growth rates is positive and slow. If technological progress would occur in every time period at a pace that increases with the above determinants, the growth rate of output per capita would always be positive, despite the adjustment in the size of population.
} 
An increase the fraction of the risk-tolerant individuals, $\beta_{t}$, has unambiguously positive effects on the level of income per worker in period $t+1, y_{t+1}=\left(A_{t+1} X / L_{t+1}\right)^{\alpha}$, in an environment where risk-tolerant individuals reproduce at lower rates than the risk averse individuals, (i.e., when $\left.y_{t}>\gamma / \tau\right)$. It raises the level of technology in period $t+1$, and reduces the population size in the population next period. However, when $y_{t}<\gamma / \tau$ and thus the risk-tolerant individuals reproduce at a higher rate, an increase the fraction of the risk-tolerant individuals in period $t$ has an ambiguous effect on output per-worker in $t+1$ since it has a positive effect on both the level of technology and population in period $t+1$.

An increase in output per capita, $y_{t}$, has ambiguous effects on the level of income per worker in period $t+1$. On the one hand it increases the level of technology in the next period, $A_{t+1}$, and thus positively affecting output per worker, but on the other hand, it increases fertility rates in period $t$, and thus the size of the population in period $t+1$, adversely affecting income per capita.

\section{The Dynamical System}

The evolution of the economy is fully determined by the evolution of a two-dimensional nonlinear discrete dynamical system that is governed by the sequence $\left\{\beta_{t}, y_{t}\right\}_{t=0}^{\infty}$ such that

$$
\begin{aligned}
& \beta_{t+1}=\phi\left(\beta_{t}, y_{t}\right) \\
& y_{t+1}=\psi\left(\beta_{t}, y_{t}\right)
\end{aligned}
$$

where $\left(\beta_{0}, y_{0}\right)$ is given.

The analysis of this two-dimensional dynamical system will require the derivation of its phase diagram, based on the characterization of the $\beta \beta$ locus under which the first state variables, the yy locus under which the second state variable is in a steady-state, and the forces that operate on the system when each of variables is not in its steady-state equilibrium.

\subsection{The $\beta \beta$ locus}

The $\beta \beta$ locus is the geometric locus of all pairs $\left(\beta_{t}, y_{t}\right)$ such that $\beta_{t}$ is in a steady state.

$$
\beta \beta \equiv\left\{\left(\beta_{t}, y_{t}\right): \beta_{t+1}-\beta_{t}=0\right\}
$$

As follows from (12), along the $\beta \beta$ locus

$$
\phi\left(\beta_{t}, y_{t}\right)-\beta_{t}=0
$$


Lemma 4 The properties of the $\beta \beta$ locus:

$$
\beta_{t+1}-\beta_{t}\left\{\begin{array}{ccc}
>0 & \text { iff } & \tilde{y}\left(\theta_{2}\right) \leq y_{t}<\gamma / \tau \\
=0 & \text { iff } \\
<0 & \text { iff } & \text { or }\left[\tilde{c}<y_{t}<\tilde{y}\left(\theta_{2}\right)\right] \text { or }\left[\beta_{t} \in\{0,1\}\right] \\
y_{t}>\gamma / \tau
\end{array}\right.
$$

Proof: As follows from (11)

$$
\beta_{t+1}-\beta_{t}=\frac{\beta_{t}\left(1-\beta_{t}\right)\left[n^{1}\left(y_{t}\right)-n^{2}\left(y_{t}\right)\right]}{\beta_{t} n^{1}\left(y_{t}\right)+\left(1-\beta_{t}\right) n^{2}\left(y_{t}\right)}
$$

Hence, as follows from Corollary

$$
\beta_{t+1}-\beta_{t}\left\{\begin{array}{ccccc}
>0 & \text { iff } & n^{1}\left(y_{t}\right)>n^{2}\left(y_{t}\right) & \text { iff } & \tilde{y}\left(\theta_{2}\right) \leq y_{t}<\gamma / \tau \\
=0 & \text { iff } & {\left[n^{1}\left(y_{t}\right)=n^{2}\left(y_{t}\right)\right]} & \text { iff } & {\left[y_{t}=\gamma / \tau\right] \text { or }\left[\tilde{c}<y_{t}<\tilde{y}\left(\theta_{2}\right)\right]} \\
<0 & \text { iff } & n^{1}\left(y_{t}\right)>n^{2}\left(y_{t}\right) & \text { iff } & \text { or }\left[\beta_{t} \in\{0,1\}\right]
\end{array} .\right.
$$

As depicted in Figure 6, the fraction of the risk tolerant individuals, $\beta_{t}$, is in a steady state if:

(a) $\beta_{t}=0$ i.e., there are only individuals of type $\theta_{2}$ in the population and thus there are only individuals of type $\theta_{2}$ in all future periods.

(b) $\beta_{t}=1$ i.e., there are only individuals of type $\theta_{1}$ in the population and thus there are only individuals of type $\theta_{1}$ in all future periods.

(c) $\left[y_{t}=\gamma / \tau\right]$ or $\left[\tilde{c}<y_{t}<\tilde{y}\left(\theta_{2}\right)\right]$, i.e., the two types reproduce at the same rate and thus there are no changes in the composition of the population over time.

\subsection{The Replacement Locus - yy ${ }^{R}$}

The replacement frontier $y y^{R}$, as depicted in Figure 6 , is the geometric locus of all pairs $\left(\beta_{t}, y_{t}\right)$ such that the average level of fertility is at replacement level, i.e.,

$$
y y^{R} \equiv\left\{\left(\beta_{t}, y_{t}\right): \beta_{t} n^{1}\left(y_{t}\right)+\left(1-\beta_{t}\right) n^{2}\left(y_{t}\right)=1\right\} .
$$

Lemma 5 The properties of the replacement locus- $y y^{R}$

1. There exists a continuous single-valued function, $y^{R}\left(\beta_{t}\right)$, such that given $\left(\beta_{t}, y^{R}\left(\beta_{t}\right)\right)$ the average fertility level is at replacement, i.e.,

$$
\left(\beta_{t}, y^{R}\left(\beta_{t}\right)\right) \in y y^{R} \quad \forall \beta_{t} \in[0,1] .
$$


2. The level of income that corresponds to replacement fertility, $y^{R}\left(\beta_{t}\right)$, is monotonically decreasing in the fraction of the risk-tolerant, $\beta_{t}$, i.e.,

$$
\left.\frac{\partial y^{R}\left(\beta_{t}\right)}{\partial \beta_{t}}\right|_{y y^{R}}<0 \quad \forall \beta_{t} \in[0,1]
$$

where

$$
\begin{aligned}
& y^{R}(1)=\tilde{c} /(1-\tau) \\
& y^{R}\left(\beta_{t}\right)<\gamma / \tau \quad \forall \beta_{t} \in[0,1]
\end{aligned} .
$$

3. The average level of fertility is below replacement if and only if $y_{t}<y_{t}^{R}\left(\beta_{t}\right)$ and above replacement if and only if $y_{t}>y^{R}\left(\beta_{t}\right)$, i.e., $\forall \beta_{t} \in[0,1]$

$$
\begin{array}{lll}
\beta_{t} n^{1}\left(y_{t}\right)+\left(1-\beta_{t}\right) n^{2}\left(y_{t}\right)<1 & \text { iff } & y_{t}<y_{t}^{R}\left(\beta_{t}\right) \\
\beta_{t} n^{1}\left(y_{t}\right)+\left(1-\beta_{t}\right) n^{2}\left(y_{t}\right)>1 & \text { iff } & y_{t}>y_{t}^{R}\left(\beta_{t}\right)
\end{array}
$$

Proof. See Appendix

The replacement locus, depicted in Figure 6, is downward sloping. ${ }^{32}$ As established in Corollary 2, as the fraction of the risk-tolerant individuals, $\beta_{t}$, increases, fertility is higher (for a given level of income below $\gamma / \tau)$, and thus the level of income that is needed to support replacement fertility, $y^{R}\left(\beta_{t}\right)$, is lower.

Corollary 3 Along the replacement locus, fertility of the risk-tolerant (type 1) is above replacement and fertility of the risk averse (type 2) is below replacement, i.e.,

$$
n^{2}\left(y^{R}\left(\beta_{t}\right)\right)<1<n^{1}\left(y^{R}\left(\beta_{t}\right)\right) \quad \forall \beta_{t} \in(0,1) .
$$

Proof. As follows from Lemma $5, \beta_{t} n^{1}\left(y_{t}^{R}\right)+\left(1-\beta_{t}\right) n^{2}\left(y_{t}^{R}\right)=1$. Hence since $\tilde{c} /(1-\tau)<$ $y^{R}\left(\beta_{t}\right)<\gamma / \tau$ it follows from Corollary 2 that $n^{1}\left(y_{t}^{R}\right)>n^{2}\left(y_{t}^{R}\right)$ and thus $n^{2}\left(y^{R}\left(\beta_{t}\right)\right)<1<$ $n^{1}\left(y^{R}\left(\beta_{t}\right)\right)$.

\subsection{The $y y$ locus}

The $y y$ locus is the geometric locus of all pairs $\left(\beta_{t}, y_{t}\right)$ such that $y_{t}$ is in a steady state.

$$
y y \equiv\left\{\left(\beta_{t}, y_{t}\right): y_{t+1}-y_{t}=0\right\} .
$$

\footnotetext{
${ }^{32}$ Without loss of generality, Figure 6 is drawn under the assumption that the $y y^{R}$ locus is convex. Note, however that as long as the locus is downward sloping the qualitative analysis remains intact.
} 
As follows from (16) and (18), along the yy locus

$$
\psi\left(\beta_{t}, y_{t}\right)-y_{t}=0
$$

and therefore

$$
y_{t+1}-y_{t}=y_{t}\left[\left(\frac{\left(1+g\left(\beta_{t}, y_{t}\right)\right)}{\beta_{t} n^{1}\left(y_{t}\right)+\left(1-\beta_{t}\right) n^{2}\left(y_{t}\right)}\right)^{\alpha}-1\right] .
$$

Hence,

$$
y_{t+1}-y_{t} \gtreqless 0 \Leftrightarrow 1+g\left(\beta_{t}, y_{t}\right) \gtreqless\left[\beta_{t} n^{1}\left(y_{t}\right)+\left(1-\beta_{t}\right) n^{2}\left(y_{t}\right)\right] .
$$

In order to simplify the exposition and to assure that the economy may escape from the Malthusian trap, few boundary conditions are imposed on the function $g\left(\beta_{t}, y_{t}\right)$.

$$
\begin{aligned}
& g_{\beta}\left(\beta_{t}, y_{t}\right)<n^{1}\left(y_{t}\right)-n^{2}\left(y_{t}\right) \quad \text { for } y_{t} \in[\tilde{c}, \breve{y}] \quad \text { if and only if } \quad \beta_{t} \in[0, \breve{\beta}] \text {; } \\
& g_{y}\left(\beta_{t}, y_{t}\right)<\beta_{t} \frac{\partial n^{1}\left(y_{t}\right)}{\partial y_{t}}+\left(1-\beta_{t}\right) \frac{\partial n^{2}\left(y_{t}\right)}{\partial y_{t}} \quad \text { if and only if } \quad y_{t} \in[\tilde{c}, \breve{y}] \\
& g\left(\beta_{t}, y_{t}\right)=\left\{\begin{array}{lll}
=0 & & y_{t} \leq y^{R}\left(\beta_{t}\right) \\
>0 & \text { if and only if } & \\
& & y_{t}>y^{R}\left(\beta_{t}\right)
\end{array}\right.
\end{aligned}
$$

where $\breve{\beta} \in(0,1)$ and $\breve{y}=y(\breve{\beta}) \in\left(y^{R}\left(\beta_{t}\right), \gamma / \tau\right)$.

Lemma 6 The properties of the yy locus.

Under (A2) and (A3)

1. There exists a continuous single-valued function, $y^{R}\left(\beta_{t}\right)$, such that

$$
\left(\beta_{t}, y^{R}\left(\beta_{t}\right)\right) \in y y \quad \forall \beta_{t} \in[0,1] .
$$

2. There exists a decreasing continuous, single-valued function $y\left(\beta_{t}\right) \in\left(y^{R}\left(\beta_{t}\right), \gamma / \tau\right)$ such that

$$
\left(\beta_{t}, y\left(\beta_{t}\right)\right) \in y y \quad \text { and } y^{\prime}\left(\beta_{t}\right)<0 \quad \forall \beta_{t} \in[0, \hat{\beta})
$$

where $\lim _{\beta_{t} \rightarrow \hat{\beta}} y\left(\beta_{t}\right)=y^{R}(\hat{\beta}), y(0) \in(\breve{y}, \gamma / \tau)$, and $\hat{\beta} \in[\breve{\beta}, 1)$.

3.

$$
y_{t+1}-y_{t}\left\{\begin{array}{lll}
<0 & \text { iff } & y^{R}\left(\beta_{t}\right)<y_{t}<y\left(\beta_{t}\right) \text { and } \beta_{t} \in[0, \hat{\beta}) \\
>0 & \text { otherwise }
\end{array}\right.
$$


Proof. See Appendix.

The yy locus and its corresponding map is depicted in Figure 6. The yy locus consists of two downward sloping segments: (i) the replacement locus $y y^{R}$, and (ii) a single value function $y\left(\beta_{t}\right)$ that intersects the $y y^{R}$ locus at $\hat{\beta}$ and the $\beta \beta$ locus at $(0, y(0))$.

\subsection{Steady-State Equilibria}

Steady-state equilibria of the dynamical system are pairs $(\bar{\beta}, \bar{y})$ such that

$$
\begin{aligned}
& \bar{\beta}=\phi(\bar{\beta}, \bar{y}) \\
& \bar{y}=\psi(\bar{\beta}, \bar{y})
\end{aligned} .
$$

Hence a steady-state equilibrium is characterized by an intersection of the $\beta \beta$ locus and the $y y$ locus. As depicted in Figure 6, the system is characterized by three steady-state equilibria.

Lemma 7 The dynamical system has three steady-state equilibria

$$
(\bar{\beta}, \bar{y})=\left\{(0, y(0)),\left(0, y^{R}(0)\right),\left(1, y^{R}(1)\right)\right\}
$$

The steady-state equilibria: $(0, y(0))$ and $\left(1, y^{R}(1)\right)$ are unstable, whereas $\left(0, y^{R}(0)\right)$, is a saddle, where

$$
\lim _{t \rightarrow \infty}\left(\beta_{t}, y_{t}\right)=\left(0, y^{R}(0)\right) \quad \text { if and only if } \beta_{0}=0
$$

Proof. The lemma follows from the properties of the $\beta \beta$ locus and the yy locus as established in Lemmas 4 and 6, and as depicted in Figure 6.

Corollary 4 If the initial fraction of risk-tolerant individuals is greater than zero, i.e., if $\beta_{0}>$ 0 , then in the long-run the fraction of risk-tolerant individuals vanishes asymptotically, whereas the level of output per-capita grows indefinitely, i.e.,

$$
\lim _{t \rightarrow \infty}\left(\beta_{t}, y_{t}\right)=(0, \infty) \quad \text { if } \beta_{0}>0
$$

Proof. The corollary follows from Lemmas 4-7, and the implied motion in Figure 6. 


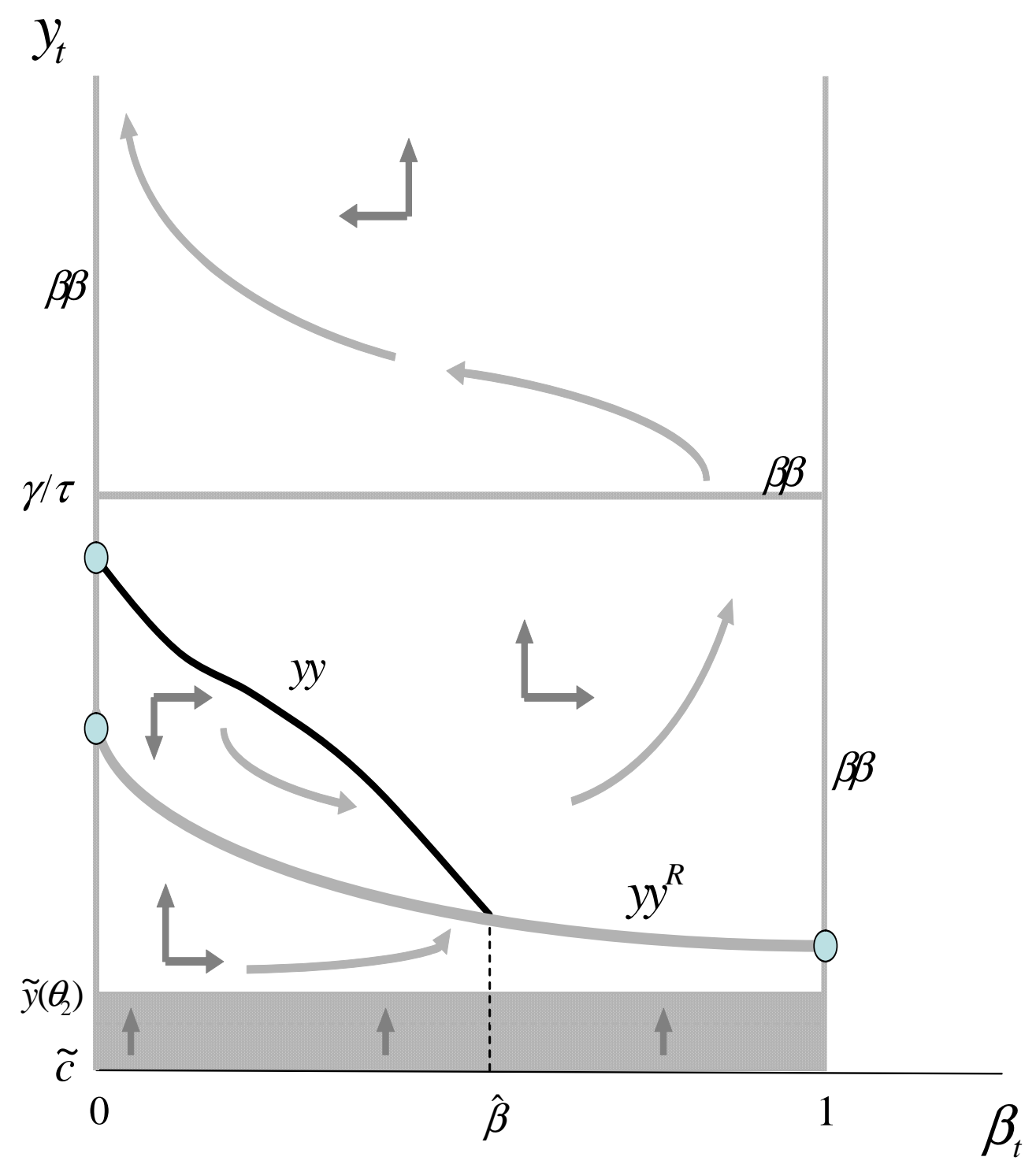

Figure 6. The Evolution of Risk Aversion and the Process of Development 


\subsection{The Evolution of Risk Aversion and the Process of Development}

Suppose that the economy starts with an income per-capita that is just sufficient to generate replacement fertility, $y^{R}\left(\beta_{0}\right)$ That is, the economy starts on the $y y^{R}$ locus. Suppose further that there is a small fraction of risk-tolerant individuals in the economy, $\beta_{0}<\hat{\beta}$. As depicted in Figure 6, the forces of natural selection will increase the representation of the risk-tolerant individual in society, and once this fraction will exceed the critical level $\hat{\beta}$, income will increase monotonically along with the fraction of the risk-tolerant individuals. Once the level of income per-capita increases above the threshold level of income $\gamma / \tau$, the subsistence consumption constraint is no longer binding for all types and the evolutionary advantage is reversed. The risk averse individuals generate an evolutionary advantage and $\beta$ starts declining approaching asymptotically 0 . Along this process income per-capita increases monotonically.

It should be noted that in the absence of the forces of natural selection the economy will remain indefinitely in a Malthusian equilibrium. That is, if the degree of risk-aversion is not hereditary and the distribution of types remains unchanged over time, the level of income per capita will remain at a level $y^{R}\left(\beta_{0}\right)$, where consumption is at the subsistence level and fertility is at replacement. This will constitute a stable Malthusian equilibrium. Technological advancement will be counterbalanced by an increase in population growth, whereas adverse technological shocks will be offset by population decline.

\section{Robustness}

\subsection{Risk Aversion with Respect to Children}

This section demonstrates that the evolutionary pattern of risk aversion in the process of development, as established in Proposition 1, remains intact if individuals are risk averse with respect to children.

Suppose that preferences of individual $i$ of generation $t$ are represented by a utility functions characterized by constant relative risk aversion with respect to children, $\lambda$, and risk attitudes with respect to consumption, $\theta_{i},{ }^{33}$

$$
u_{t}^{i}=\frac{\left(c_{t}^{i}\right)^{1-\theta_{i}}}{1-\theta_{i}}+\gamma \frac{\left(n_{t}^{i}\right)^{1-\lambda}}{1-\lambda} .
$$

Members of generation $t$ choose the number of their children, and therefore their own

\footnotetext{
${ }^{33}$ The linear utility with respect to children examined in section 3 is a subset of this more general class of preferences. It is obtained at $\lambda=0$.
} 
consumption, so as to maximize the utility function (28) subject to their budget and the subsistence consumption constraints. Substituting (4) into (28), the optimization problem of a member of generation $t$ is:

$$
n_{t}^{i}=\operatorname{argmax}\left\{\frac{\left[y_{t}\left(1-n_{t}^{i} \tau\right)\right]^{\left(1-\theta_{i}\right)}}{\left(1-\theta_{i}\right)}+\gamma \frac{\left(n_{t}^{i}\right)^{1-\lambda}}{1-\lambda}\right\}
$$

Subject to: ${ }^{34}$

$$
\begin{aligned}
& c_{t}^{i}=y_{t}\left(1-n_{t}^{i} \tau\right) \geq \tilde{c}=0 \\
& n_{t}^{i} \geq 0 .
\end{aligned}
$$

The solution of the optimization problem is interior. ${ }^{35}$ It is given by the implicit function

$$
\digamma\left(n_{t}^{i}, \theta_{i}\right)=\gamma\left(n_{t}^{i}\right)^{-\lambda}-y_{t} \tau\left[y_{t}\left(1-n_{t}^{i} \tau\right)\right]^{-\theta_{i}} \equiv 0 .
$$

As established in the following Lemma, the effect of risk aversion with respect to consumption on reproductive success evolves non-monotonically in the process of development, as was the case when the utility function was linear with respect to children. At low levels of income individuals characterized by low degree of risk aversion have the evolutionary advantage, whereas at high levels of income the more risk averse take over. More specifically, risk-tolerant individuals with respect to consumption maintain the evolutionary advantage. The higher is their risk aversion with respect to children the earlier will be the reversal in the evolutionary advantage, in favor of the higher $\theta_{i}$ types.

Proposition 2 The effect of risk aversion with respect to consumption on reproductive success evolves non-monotonically in the process of development

$$
\frac{\partial n_{t}^{i}}{\partial \theta_{i}}\left\{\begin{array}{l}
<0 \text { if }\left\{\begin{array}{l}
\tilde{c}<y_{t}<1 /(1-\tau) \\
\left.1 /(1-\tau)<y_{t}<\gamma / \tau\right] \text { and }\left[\lambda<\ln \left(\gamma / \tau y_{t}\right) / \ln \left(\left[1-\left(1 / y_{t}\right)\right] / \tau\right)\right.
\end{array}\right. \\
>0 \text { if }\left\{\begin{array}{l}
1 /(1-\tau)<y_{t}<\gamma / \tau \text { and }\left[\lambda>\ln \left(\gamma / \tau y_{t}\right) / \ln \left(\left[1-\left(1 / y_{t}\right)\right] / \tau\right)\right. \\
y_{t} \geq \gamma / \tau
\end{array}\right.
\end{array}\right.
$$

\footnotetext{
${ }^{34}$ For the simplicity of the exposition, $\tilde{c}=0$. This simplification does not affect the qualitative results as long as $\tilde{c}<1$. Moreover, in light of the results obtained in section 3 , the reversal in the evolutionary advantage occurs only after the subsistence consumption constraint stops binding for both types of individuals.

${ }^{35}$ If either $n_{t}^{i}=0$ or $c_{t}^{i}=0$ then the marginal cost of such a decision in terms of utility is infinite. Hence, an individual with a positive level of income will allocate a positive amount of resources to both consumption and children.
} 
Proof. See Appendix.

Given a common degree of risk aversion with respect to children the marginal utility of consumption depends on the level of income and the degree of risk aversion with respect to consumption.

At low levels of income, $y_{t}<1 /(1-\tau)$, when relative prices are in favor of child rearing the more risk averse individuals with respect to consumption will reproduce at a slower rate than those individuals who are relatively more risk-tolerant with respect to consumption irrespective of the degree of risk aversion with respect to children.

At sufficiently high levels of income, i.e., $y_{t}>\gamma / \tau$, the marginal utility from consumption, for a given level of income, is lower the higher is the degree of risk aversion with respect to consumption, and hence, more resources will be devoted to children. Consequently, fertility is higher the higher is the degree of risk aversion with respect to consumption, and the high risk averse type has an evolutionary advantage. Note that differences in the degree of risk aversion with respect to children do not affect the evolutionary advantage.

It is in intermediate stages of development, i.e., $1 /(1-\tau)<y_{t}<\gamma / \tau$ that the degree of risk aversion with respect to children affects the timing of the reversal in the evolutionary advantage of the two types. The risk tolerant individuals with respect to consumption will lose their evolutionary advantage earlier, in this stage, the higher is the degree of risk aversion with respect to children.

\subsection{Extinction of Risk-Seeking Behavior}

This section establishes that the exclusion of risk-seeking behavior from the analysis is justified, because if the trait of risk-seeking behavior (i.e., $\theta_{i}<0$ ) was present in the population in the distant past, it would have become extinct.

Proposition 3 Individuals that are characterized by risk-seeking behavior, (i.e., those whose $\left.\theta_{i}<0\right)$ will become extinct in early stages of development, i.e., for $\theta_{i}<0$

$$
n^{i}\left(y_{t}\right)=0 \quad \text { if } \quad y_{t} \leq(\gamma / \tau)^{1 /\left(1-\theta_{i}\right)}
$$

Proof. As follows from (4), the non negative fertility constraint binds and fertility is zero as long as the optimal level of consumption is at least equal to the level output per worker. Namely, 


$$
n_{t}^{i}\left(y_{t}\right)=0 \quad \text { iff } \quad c_{t} / y_{t} \geq 1
$$

Hence, since $c_{t}^{i}=\left[\tau y_{t} / \gamma\right]^{1 / \theta_{i}}$, it follows that $c_{t} / y_{t} \geq 1$ if and only if $[\tau / \gamma]^{1 / \theta_{i}} \geq y_{t}^{\left(\theta_{i}-1\right) / \theta_{i}}$, and therefore, if and only if $\left(1 / \theta_{i}\right) \ln (\tau / \gamma) \leq\left(\theta_{i}-1\right) / \theta_{i} \ln y_{t}$. Thus, $n_{t}^{i}\left(y_{t}\right)=0$ if and only if $\ln y_{t} \leq \ln (\gamma / \tau)^{1 /\left(1-\theta_{i}\right)}$ and therefore, $y_{t} \leq(\gamma / \tau)^{1 /\left(1-\theta_{i}\right)}$.

\subsection{Risk Aversion is Distributed over the Entire Feasible Range}

This section demonstrates that the evolutionary pattern of risk aversion in the process of development, as established in Proposition 1, remains intact if risk aversion is distributed over the entire feasible range (i.e., if $\theta \epsilon(0,1) \cup(\bar{\theta}, \infty))$. The case of $\theta \epsilon(1, \bar{\theta})$ has been already analyzed.

Lemma 8 The subsistence consumption constraint $\tilde{y}^{i}=\tilde{y}\left(\theta_{i}\right) \equiv(\gamma / \tau) \tilde{c}^{\theta_{i}}$ binds only for individuals with $\theta \in(0, \bar{\theta})$.

Proof: As established in Lemma (1), $\tilde{y}\left(\theta_{i}\right) \equiv(\gamma / \tau) \tilde{c}^{\theta_{i}}$. Hence, the subsistence consumption constraint binds if $\tilde{y}\left(\theta_{i}\right) \geq \tilde{c}$, i.e., if $(\gamma / \tau) \tilde{c}^{\theta_{i}} \geq \tilde{c}$ and therefore if

$$
\theta_{i} \leq 1+\ln (\tau / \gamma) / \ln \tilde{c} \equiv \bar{\theta}
$$

Lemma 9 There exists a threshold level of income $\hat{y}\left(\theta_{i}\right) \equiv(\gamma / \tau)^{1 /\left(1-\theta_{i}\right)}$ such that the nonnegative fertility constraint binds above $\hat{y}\left(\theta_{i}\right)$ if and only if $\theta_{i} \epsilon(0,1)$, and below $\hat{y}\left(\theta_{i}\right)$ if and only if $\theta_{i} \in(\bar{\theta}, \infty)$, i.e.,

$$
n_{t}^{i}=0 \text { if } y_{t}>\hat{y}\left(\theta_{i}\right) \text { and } \theta_{i} \epsilon(0,1) \quad \text { or } y_{t}<\hat{y}\left(\theta_{i}\right) \text { and } \theta_{i} \epsilon(\bar{\theta}, \infty)
$$

Proof. As follows from (4) and the strong monotonicity of the utility function, $n_{t}^{i} \geq 0$ if and only if $c_{t}^{i}=\left[\tau y_{t} / \gamma\right]^{1 / \theta_{i}} \leq y_{t}$, and therefore, if and only if $c_{t} \leq y_{t}$, or $\left(\tau y_{t} / \gamma\right)^{1 / \theta_{i}} \leq y_{t}$. Hence,

$$
n_{t}^{i} \geq 0 \quad \text { if and only if } \quad\left(\theta_{i}-1\right) \ln y_{t} \geq \ln (\tau / \gamma)
$$

Hence,

$$
n_{t}^{i} \geq 0 \text { iff }\left\{y_{t} \leq \hat{y}\left(\theta_{i}\right) \text { and } \theta_{i} \epsilon(0,1) \quad \text { or } \quad y_{t} \geq \hat{y}\left(\theta_{i}\right) \text { and } \theta_{i}>\bar{\theta}\right\}
$$


where $\hat{y}\left(\theta_{i}\right) \equiv(\gamma / \tau)^{\frac{1}{1-\theta_{i}}}$. Hence,

$$
n_{t}^{i}=0 \text { iff }\left\{y_{t} \geq \hat{y}\left(\theta_{i}\right) \text { and } \theta_{i} \epsilon(0,1) \text { or } y_{t} \leq \hat{y}\left(\theta_{i}\right) \text { and } \theta_{i}>\bar{\theta}\right\}
$$

and the lemma follows.

Hence, it follows from lemmas 8 and 9 , noting that $\tilde{y}\left(\theta_{i}\right) \leq \hat{y}\left(\theta_{i}\right)$ if $\theta \in(0,1)$, that the levels of consumption and fertility are:

$$
\begin{aligned}
& \left\{\begin{array}{l}
c_{t}^{i}=\tilde{c} \\
n_{t}^{i}=\left[1-\left(\tilde{c} / y_{t}\right)\right] / \tau
\end{array} \quad \text { if } \quad \tilde{c} \leq y_{t} \leq \tilde{y}\left(\theta_{i}\right) \text { and } \theta \in(0,1)\right. \\
& \left\{\begin{array}{ccc}
c_{t}^{i}=\left(\tau y_{t} / \gamma\right)^{1 / \theta_{i}} & & \\
& \text { if } & \\
& & y_{t} \geq \hat{y}\left(\theta_{i}\right) \leq y_{t} \leq \hat{y}\left(\theta_{i}\right) \text { and } \theta \epsilon(\bar{\theta}, \infty) \\
n_{t}^{i}=\left[1-(\tau / \gamma)^{1 / \theta_{i}} y_{t}^{\left(1-\theta_{i}\right) / \theta_{i}}\right] / \tau & &
\end{array}\right.
\end{aligned}
$$

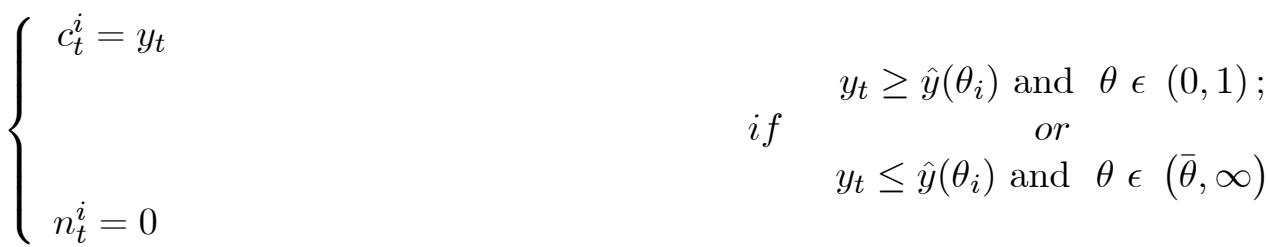

Moreover,

$$
\frac{\partial n_{t}}{\partial y_{t}}=\left\{\begin{array}{ccc}
\leq 0 & \text { if } & y_{t}>\tilde{y}\left(\theta_{i}\right) \\
\geq 0 & \text { and } \quad \theta_{i} \in(0,1)
\end{array} .\right.
$$

Hence, the enlargement of the feasible range $\theta_{i}$ does not affect the qualitative pattern of the evolution of risk-aversion as established in Proposition 1.

The introduction of the least risk averse individuals in the population, i.e., individuals with $\theta_{i} \in(0,1)$, does not affect the reversal in the evolutionary advantage of the risk-tolerant individuals. As follows from Lemma 1, the least risk averse individuals in the population, i.e., individuals with $\theta_{i} \in(0,1)$, are constrained by the subsistence consumption constraint for a wider income range, and thus their evolutionary advantage is accentuated over a wider range of low levels of income. However, as follows in Proposition (1) once $y_{t}$ exceeds the threshold value of $\gamma / \tau$ they lose the evolutionary advantage to the more risk averse individuals since the effect of risk aversion on fertility becomes positive (for the entire feasible range of $\theta_{i}$ ).

The introduction of the more risk averse individuals i.e., those with $\theta_{i} \in(\bar{\theta}, \infty)$ does not affect the qualitative results either. As follows from Lemma 9, at low levels of income (i.e., 
if $\left.y_{t} \leq \hat{y}\left(\theta_{i}\right)\right)$ they would become extinct, and at a moderate levels of income, (i.e., $\hat{y}\left(\theta_{i}\right) \leq$ $\left.y_{t}<\gamma / \tau\right)$, as follows from Proposition (1), they would produce consistently fewer children. However, for $y_{t}>\gamma / \tau$ they would gain the evolutionary advantage.

\subsection{Variations in the Risk Attitude Towards Children}

This section demonstrates that the evolutionary pattern of risk aversion in the process of development, as established in Proposition 1, remains intact if heterogeneity is introduced with respect to the risk attitude with respect to children. In particular, it demonstrates that risk neutrality with respect to children is the type of behavior that would be selected in populations that have been expanding over time, and thus the utility function that is adopted in the main analysis is the appropriate one.

Suppose that preferences of individuals $i$ are represented by utility functions with (homogeneous) constant relative risk aversion with respect to consumption, $\theta$, and (heterogeneous) risk attitudes with respect to children, $\lambda_{i}$,

$$
u_{t}^{i}=\frac{\left(c_{t}^{i}\right)^{1-\theta}}{1-\theta}+\gamma \frac{\left(n_{t}^{i}\right)^{1-\lambda_{i}}}{1-\lambda_{i}} . \quad \lambda_{i} \geq 0
$$

Members of generation $t$ choose the number of the children, and therefore own consumption, so as to maximize the utility function (35) subject to the budget and the subsistence consumption constraints. Substituting (4) into (35), the optimization problem of a member of generation $t$ is:

$$
n_{t}^{i}=\operatorname{argmax}\left\{\frac{\left[y_{t}\left(1-n_{t}^{i} \tau\right)\right]^{(1-\theta)}}{(1-\theta)}+\gamma \frac{\left(n_{t}^{i}\right)^{1-\lambda_{i}}}{1-\lambda_{i}}\right\}
$$

Subject to: ${ }^{36}$

$$
\begin{aligned}
& c_{t}^{i}=y_{t}\left(1-n_{t}^{i} \tau\right) \geq \tilde{c}=0 \\
& n_{t}^{i} \geq 0 .
\end{aligned}
$$

The solution of the optimization problem is interior. It is given by the implicit function

$$
\digamma\left(n_{t}^{i}, \lambda_{i}\right)=\gamma\left(n_{t}^{i}\right)^{-\lambda_{i}}-y_{t} \tau\left[y_{t}\left(1-n_{t}^{i} \tau\right)\right]^{-\theta} \equiv 0 .
$$

As established in the following Lemma, as long as fertility rates are above replacement the more risk tolerant type in terms of children has the evolutionary advantage. If fertility rates are below replacement (and the population therefore vanishes over time), the type that is more risk averse with respect to children gains an evolutionary advantage .

\footnotetext{
${ }^{36}$ For the simplicity of the exposition, $\tilde{c}=0$.
} 
Proposition 4 The effect of risk aversion with respect to fertility on reproductive success is negative as long as fertility is above replacement and is positive as long as fertility is below replacement.

$$
\frac{\partial n_{t}^{i}}{\partial \lambda_{i}}\left\{\begin{array}{l}
<0 \text { iff }\left\{n_{t}^{i}>1\right. \\
=0 \text { iff }\left\{n_{t}^{i}=1\right. \\
>0 \text { iff }\left\{n_{t}^{i}<1\right.
\end{array}\right.
$$

Proof. Using the Implicit Function Theorem, it follows from (37) that

$$
\frac{\partial n_{t}^{i}}{\partial \lambda_{i}}=-\frac{\partial \digamma\left(n_{t}^{i}, \lambda_{i}\right) / \partial \lambda_{i}}{\partial \digamma\left(n_{t}^{i}, \lambda_{i}\right) / \partial n_{t}^{i}}=-\frac{-\gamma\left(n_{t}^{i}\right)^{-\lambda_{i}} \ln n_{t}^{i}}{-\lambda \gamma\left(n_{t}^{i}\right)^{-\lambda_{i}-1}-\theta\left(y_{t} \tau\right)^{2}\left[y_{t}\left(1-n_{t}^{i} \tau\right)\right]^{-\theta-1}} .
$$

where,

$$
\begin{aligned}
& \frac{\partial \digamma\left(n_{t}^{i}, \lambda_{i}\right)}{\partial \lambda_{i}}\left\{\begin{array}{rlr}
<0 & \text { if } & n_{t}^{i}>1 \\
>0 & \text { if } & n_{t}^{i}<1
\end{array}\right. \\
& \frac{\partial \digamma\left(n_{t}^{i}, \lambda_{i}\right)}{\partial n_{t}^{i}}<0
\end{aligned}
$$

Hence,

$$
\operatorname{sign}\left[\frac{\partial n_{t}^{i}}{\partial \lambda_{i}}\right]=\operatorname{sign}\left[\frac{\partial \digamma\left(n_{t}^{i}, \lambda_{i}\right)}{\partial \lambda_{i}}\right]\left\{\begin{array}{ccc}
>0 & \text { if } & n_{t}^{i}<1 \\
<0 & \text { if } & n_{t}^{i}>1
\end{array} .\right.
$$

Hence the lemma follows from (40)

Since the human population has not become extinct, fertility has not been below replacement and the distribution of risk attitudes with respect to children will converge towards risk-neutrality in the long-run. ${ }^{37}$

Corollary 5 Risk neutrality with respect to children, i.e., $\lambda_{i}=0$, will be selected in the longrun.

Hence, risk neutrality with respect to children, $\lambda_{i}=0$, that was imposed on our utility function in the main part of the paper, is the trait that will be selected in the long-run.

\footnotetext{
${ }^{37}$ Segments of the human population that have been shrinking over time, but have not become extinct, would compose of more risk averse individuals with respect to fertility.
} 


\subsection{The Old Age Security Hypothesis}

This section demonstrates that the evolutionary pattern of risk aversion in the process of development, as established in Proposition 1, remains intact if the incentive of individuals to have children is enhanced by the material support that children may provide to their parents in old age - The Old Age Security Hypothesis.

Suppose that individuals within each generation live for three period. In the first period of life (childhood), individuals consume a fraction of their parental income, $\tau$. In the second period of life (parenthood), individuals are endowed with 1 unit of time. They work and generate an an income $y_{t}$, which they allocate between consumption, $c_{t}^{i}$, child rearing, $\tau y_{t} n_{t}^{i}$, and transfers to their parents $z$. In the third period (old age), individuals consume the aggregate output transferred to them by their children, $z n_{t}^{i}$.

Preferences of individuals $i$ are represented by a separable utility function with (heterogeneous) constant relative risk aversion with respect to consumption, $\theta_{i}$, in both periods $t$ and $t+1 .^{38}$

$$
u_{t}^{i}=\frac{\left(c_{t}^{i}\right)^{1-\theta_{i}}}{1-\theta_{i}}+\gamma \frac{\left(c_{t+1}^{i}\right)^{1-\theta_{i}}}{1-\theta_{i}} .
$$

Members of generation $t$ choose the number of their children, and therefore their own consumption in periods $t$ and $t+1$, so as to maximize the utility function (41) subject to the following constraints.

$$
\begin{array}{cl}
\left(c_{t}^{i}, c_{t+1}^{i}, n_{t}^{i}\right) & \geqslant 0 \\
y_{t} \tau n_{t}^{i}+c_{t}^{i}+z & \leq y_{t} \\
c_{t+1}^{i} & \leq z n_{t}^{i}
\end{array}
$$

Substituting (??) into (41), the optimization problem of a member of generation $t$ is:

$$
n_{t}^{i}=\operatorname{argmax}\left\{\frac{\left[y_{t}\left(1-n_{t}^{i} \tau\right)-z\right]^{1-\theta_{i}}}{1-\theta_{i}}+\gamma \frac{\left(z n_{t}^{i}\right)^{1-\theta_{i}}}{1-\theta_{i}}\right\}
$$

Subject to $\left(c_{t}^{i}, c_{t+1}^{i}\right)>0 .^{39}$

The solution of the optimization problem is necessarily interior and it is given by the implicit function

\footnotetext{
${ }^{38}$ A direct utility from children along with the old-age security would not affect the qualitative results. Additionally, it will become apparent, from this robustness check, that if individuals had common risk aversion, $\theta_{i}$, over both consumption and children (with or without a direct concern for old age consumption), that is if preferences were homothetic, then all the results presented would remain intact.

${ }^{39}$ For the simplicity of the exposition, $\tilde{c}=0$ for both periods.
} 


$$
\digamma\left(n_{t}^{i}, \theta_{i}\right)=\gamma z\left(z n_{t}^{i}\right)^{-\theta_{i}}-y_{t} \tau\left[y_{t}\left(1-n_{t}^{i} \tau\right)-z\right]^{-\theta_{i}} \equiv 0 .
$$

As established in the following Lemma, the effect of risk aversion with respect to consumption on reproductive success evolves non-monotonically in the process of development, as was the case in the absence of old age consumption motive for having children.

Proposition 5 The effect of risk aversion with respect to consumption on reproductive success evolves non-monotonically in the process of development when old age support is allowed.

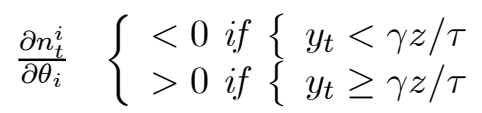

Proof. Using the Implicit Function Theorem, it follows from (44) that

$$
\frac{\partial n_{t}^{i}}{\partial \theta_{i}}=-\frac{\partial \digamma\left(n_{t}^{i}, \theta_{i}\right) / \partial \theta_{i}}{\partial \digamma\left(n_{t}^{i}, \theta_{i}\right) / \partial n_{t}^{i}}
$$

Since the second order condition for the maximization of (43) implies that $\partial \digamma\left(n_{t}^{i}, \theta_{i}\right) / \partial n_{t}^{i}<0$, it follows that,

$$
\operatorname{sign}\left[\frac{\partial n_{t}^{i}}{\partial \theta_{i}}\right]=\operatorname{sign}\left[\frac{\partial \digamma\left(n_{t}^{i}, \theta_{i}\right)}{\partial \theta_{i}}\right]=\operatorname{sign}\left[-\left(1 / \theta_{i}\right)^{2} \ln \left(\gamma z / y_{t} \tau\right)\right]\left\{\begin{array}{ccc}
<0 & \text { if } & y_{t}<\gamma z / \tau \\
>0 & \text { if } & y_{t} \geq \gamma z / \tau
\end{array} .\right.
$$

The reversal stems from the effect of the level of income on the relative cost of third period consumption relative to second period consumption. Old age consumption is secured via the production of children. In early stages of development, income is low, the cost of children is low and thus the cost of third period consumption relative to second period consumption is low. Hence, risk tolerant individuals whose choices are more responsive to the relative prices, optimally allocate more resources towards the (cheaper) old-age consumption and thus to child rearing, and the representation of their type increases in the population over time. As the economy develops and income increases, the cost of raising children and thus old age consumption is eventually higher than the cost of second period consumption. The less risk averse individuals, who are more responsive in their choices to relative prices, optimally allocate more resources towards second period consumption and less toward children. Hence, the more risk averse individuals allocate relatively more resources towards fertility and gain the evolutionary advantage. ${ }^{40}$

\footnotetext{
${ }^{40}$ It should be noted that in a stochastic environment children reduce the risk in old age consumption, but
} 


\section{Concluding Remarks}

This research suggests that the evolution of entrepreneurial spirit played a significant role in the process of economic development and the evolution of inequality within and across societies.

The study argues that traits for entrepreneurial spirit evolved non-monotonically in the course of human history. In early stages of development, the rise in income generated an evolutionary advantage to entrepreneurial, growth promoting traits and their increased representation accelerated the pace of technological advancements and the process of economic development. Natural selection therefore had magnified growth promoting activities in relatively wealthier economies as well as within the upper segments of societies, enlarging the income gap within as well as across societies. In mature stages of development, however, nonentrepreneurial individuals gained an evolutionary advantage diminishing the growth potential of advanced economies. Hence, the forces of natural selection contributed to the convergence of the intermediate level economies to the advanced ones, as well as to the convergence of entrepreneurs among the middle class to the landed aristocracy. Recent findings by Koren and Tenreyro (2007) support this hypothesis demonstrating that specialization in early stages of development occurs in sectors exhibiting higher risk whereas in mature stages of development in lower risk sectors flourish.

The research identifies a novel force that operates towards a convergence of intermediate level economies to the richer ones. Unlike the commonly underlined forces of economic convergence (i.e., higher returns in laggard economies to investments in human capital, physical capital and technological adoptions), the research suggests that convergence is triggered by the higher prevalence of individuals with entrepreneurial traits in the middle income economies.

The prediction of the theory regarding the evolution of inequality and entrepreneurial activities within a society is consistent with the pattern observed in England during the course of the Industrial Revolution. In particular the theory suggests that the failure of the landed aristocracy to lead the risky process of industrialization could be attributed to the low representation of entrepreneurial individuals within this group, and the prevalence of individuals with risk tolerant entrepreneurial traits among the middle and even the lowers class. The rise in inequality that characterized the early stages of the Industrial Revolution was therefore reversed and inequality started to decline.

increase consumption risk in the second period (parenthood) since a larger family will be harder to sustain in a case of an adverse shock (e.g. famine). For instance Meng and Qian (2006) show that during the Great famine in China, the number of surviving children is smaller in the more affluent regions (the region, which, given a Malthusian environment, had presumably a higher number of children). 
The analysis is conducted in a deterministic environment. The abstraction from a stochastic environment is merely a simplifying modeling assumption that prevents the introduction of an additional dimension of heterogeneity across individuals - income. The incorporation of idiosyncratic risky choices would enhance the evolutionary advantage of the risk tolerant entrepreneurial individuals in early stages of development. To the extent that risk tolerant individuals manifest their propensity towards risk by undertaking relatively riskier, higher payoff projects, they would generate on average higher income, and thus in this era in which larger income is converted into larger number of surviving offspring, their evolutionary advantage would be accentuated. At higher stages of economic development, the higher earning capacity of the risk-tolerant individuals would mitigate the evolutionary advantage of the risk-averse individuals. However, if the proposed theory would be embedded in the context of a unified growth theory [Galor (2005)] in which economies evolve endogenously from a Malthusian stagnation to sustained economic growth, and higher income has no longer a positive effect on fertility (Galor and Weil (2000)), ${ }^{41}$ the selection of the risk averse individuals would remain unambiguous, although it would be obscured by a more elaborate structure. ${ }^{42}$

\footnotetext{
${ }^{41}$ See also, Lagerlof (2003), Doepke (2004), and Weisdorf (2004) as well.

${ }^{42}$ The introduction of aggregate shocks would not affect the qualitative results. Aggregate shocks (e.g., major climatic shocks) had been impacting the whole population in early stages of development. It is implausible, given the nature of the technology in this period, that such shocks had a systematically differential impact on certain type of individuals, based upon their actions. Furthermore, to the extent that individual projects were undertaken after aggregate uncertainty was resolved, the risk tolerant type would retain the evolutionary advantage.
} 


\section{Appendix}

\section{Proof of Lemma 2.}

1. As follows from (4), as long as the subsistence consumption constraint binds, $n_{t}^{i}=[1-$ $\left.\left(\tilde{c} / y_{t}\right)\right] / \tau \geq 1$ if and only if $y_{t} \geq \tilde{c} /(1-\tau)$, where $\tilde{c} /(1-\tau)<1$.

2. As follows from (7) and (8) $n^{i}\left(y_{t}\right)>1$ for all $y_{t} \geq \gamma / \tau$ if $n^{i}(\gamma / \tau)>1$ and therefore if $[1-(\tau / \gamma)] / \tau>1$, which is satisfied since $\tau<1-\tau$ and $\gamma>1$

\section{Proof of Lemma 3.}

1. As follows directly from $(11), \phi\left(0, y_{t}\right)=0$ and $\phi\left(1, y_{t}\right)=1$.

2. Differentiating(12),

$$
\phi_{\beta}\left(\beta_{t}, y_{t}\right)=\frac{n_{t}^{1} n_{t}^{2}}{\left[\beta_{t} n_{t}^{1}+\left(1-\beta_{t}\right) n_{t}^{2}\right]^{2}}>0,
$$

and as follows from Corollary 2

$$
\phi_{\beta \beta}\left(\beta_{t}, y_{t}\right)=\frac{2 n_{t}^{1} n_{t}^{2}\left(n_{t}^{1}-n_{t}^{2}\right)}{\left[\beta_{t} n_{t}^{1}+\left(1-\beta_{t}\right) n_{t}^{2}\right]^{3}}\left\{\begin{array}{ccc}
<0 & \text { if } & \tilde{y}\left(\theta_{2}\right)<y_{t}<\gamma / \tau \\
\geq 0 & \text { if } & y_{t} \geq \gamma / \tau
\end{array} .\right.
$$

\section{Proof of Lemma 5.}

1. As follows from (24) there exists a function $\Omega\left(\beta_{t}, y_{t}^{R}\right)$ such that

$$
\Omega\left(\beta_{t}, y_{t}^{R}\right)=\beta_{t} n^{1}\left(y_{t}^{R}\right)+\left(1-\beta_{t}\right) n^{2}\left(y_{t}^{R}\right)-1 \equiv 0 .
$$

Hence, noting (8),

$$
\partial \Omega\left(\beta_{t}, y_{t}^{R}\right) / \partial y_{t}^{R}=\beta_{t} \frac{\partial n^{1}\left(y_{t}^{R}\right)}{\partial y_{t}^{R}}+\left(1-\beta_{t}\right) \frac{\partial n^{2}\left(y_{t}^{R}\right)}{\partial y_{t}^{R}}>0 .
$$

Thus, noting (50), it follows from the Implicit Function Theorem, that there exists a continuous single-valued function, $y^{R}\left(\beta_{t}\right)$, such that

$$
\left(\beta_{t}, y^{R}\left(\beta_{t}\right)\right) \in y y^{R} \quad \forall \beta_{t} \in[0,1]
$$

2. As follows from $(24)$ 


$$
\left.\frac{\partial y^{R}\left(\beta_{t}\right)}{\partial \beta_{t}}\right|_{y y^{R}}=-\frac{\partial \Omega\left(\beta_{t}, y_{t}^{R}\right) / \partial \beta_{t}^{R}}{\partial \Omega\left(\beta_{t}, y_{t}^{R}\right) / \partial y_{t}^{R}}=-\frac{n^{1}\left(y_{t}^{R}\right)-n^{2}\left(y_{t}^{R}\right)}{\beta_{t} \frac{\partial n^{1}\left(y_{t}^{R}\right)}{\partial y_{t}^{R}}+\left(1-\beta_{t}\right) \frac{\partial n^{2}\left(y_{t}^{R}\right)}{\partial y_{t}^{R}}} .
$$

Lemma 2 and Corollary (2) imply that

$$
n^{1}(\gamma / \tau)=n^{2}(\gamma / \tau)>1
$$

and thus it follows that the average level of fertility will be at replacement level only if

$$
y^{R}\left(\beta_{t}\right)<\gamma / \tau \quad \forall \beta_{t} \in[0,1] .
$$

Hence, it follows from Corollary (2) that $n^{1}\left(y_{t}^{R}\right)-n^{2}\left(y_{t}^{R}\right)>0$, and therefore, in light of (50), it follows from (52), that

$$
\left.\frac{\partial y^{R}\left(\beta_{t}\right)}{\partial \beta_{t}}\right|_{y y^{R}}<0 \quad \forall \beta_{t} \in[0,1] .
$$

Finally, noting (49), $y^{R}(1)$ is given by the solution to $n^{1}\left(y_{t}^{R}\right)=1$, and therefore it follows from (7) that

$$
y^{R}(1)=\tilde{c} /(1-\tau)<1
$$

since $\tilde{c}<(1-\tau)$.

3. Noting (8) fertility is positively affected by output per worker, and thus it follows from (24) that for any $\beta_{t} \in[0,1]$

$$
\beta_{t} n^{1}\left(y_{t}^{R}\right)+\left(1-\beta_{t}\right) n^{2}\left(y_{t}^{R}\right) \lesseqgtr 1 \forall y_{t} \lesseqgtr y_{t}^{R}\left(\beta_{t}\right)
$$

\section{Proof of Lemma 6.}

1. As established in (27), $y_{t+1}-y_{t}=0$ if and only if

$$
1+g\left(\beta_{t}, y_{t}\right)=\left[\beta_{t} n^{1}\left(y_{t}\right)+\left(1-\beta_{t}\right) n^{2}\left(y_{t}\right)\right] .
$$

Hence since $\left[\beta_{t} n^{1}\left(y_{t}^{R}\right)+\left(1-\beta_{t}\right) n^{2}\left(y_{t}^{R}\right)\right]=1$, and $g\left(\beta_{t}, y_{t}^{R}\right)=0$ it follows that $\left(\beta_{t}, y^{R}\left(\beta_{t}\right)\right) \in$ yy $\forall \beta_{t} \in[0,1]$.

2. As established in (25), $y_{t+1}-y_{t}=0$ if and only if $\psi\left(\beta_{t}, y_{t}\right)-y_{t}=0$. As follows from (27),

$$
\left.\frac{\partial y_{t}}{\partial \beta_{t}}\right|_{y_{t+1}-y_{t}=0}=\frac{\left\{\left[n^{1}\left(y_{t}\right)-n^{2}\left(y_{t}\right)\right]-g_{\beta}\left(\beta_{t}, y_{t}\right)\right\}}{\left\{g_{y}\left(\beta_{t}, y_{t}\right)-\left[\beta_{t} \frac{\partial n^{1}\left(y_{t}\right)}{\partial y_{t}}+\left(1-\beta_{t}\right) \frac{\partial n^{2}\left(y_{t}\right)}{\partial y_{t}}\right]\right\}}
$$


Hence, it follows from (A3) that along the yy locus, that denominator does not vanish, and there exists a decreasing continuous, single-valued function $y\left(\beta_{t}\right) \in\left(y^{R}\left(\beta_{t}\right), \gamma / \tau\right)$ such that

$$
\left(\beta_{t}, y\left(\beta_{t}\right)\right) \in y y
$$

where $\forall \beta_{t} \in[0, \hat{\beta})$

$$
\left.\frac{\partial y_{t}}{\partial \beta_{t}}\right|_{y_{t+1}-y_{t}=0}<0
$$

Moreover, as follows from the Intermediate Value Theorem, noting (A3), $\lim _{\beta_{t} \rightarrow \hat{\beta}} y\left(\beta_{t}\right)=y^{R}(\hat{\beta})$, $y(0) \in(\breve{y}, \gamma / \tau)$, and $\hat{\beta} \in[\breve{\beta}, 1)$.

3. As established in Lemma $2, \beta_{t} n^{1}\left(y_{t}\right)+\left(1-\beta_{t}\right) n^{2}\left(y_{t}\right)<1$ iff $y_{t}<y_{t}^{R}\left(\beta_{t}\right)$. Hence since $g\left(\beta_{t}, y_{t}\right)=0$ for all $y_{t} \leq y_{t}^{R}$, it follows that

$$
y_{t+1}-y_{t}>0 \quad \text { if } \quad \tilde{c}<y_{t} \leq y_{t}^{R}
$$

As follows form Assumption (A3), $y_{t+1}-y_{t}<0$ if and only if $y^{R}\left(\beta_{t}\right)<y_{t}<y\left(\beta_{t}\right)$ and $\beta_{t} \in[0, \hat{\beta})$.

Proof of Proposition 2: Using the Implicit Function Theorem, it follows from (30) that

$$
\frac{\partial n_{t}^{i}}{\partial \theta_{i}}=-\frac{\partial \digamma\left(n_{t}^{i}, \theta_{i}\right) / \partial \theta_{i}}{\partial \digamma\left(n_{t}^{i}, \theta_{i}\right) / \partial n_{t}^{i}}=-\frac{y_{t}\left[\tau y_{t}\left(1-n_{t}^{i} \tau\right)\right]^{-\theta_{i}} \ln y_{t}\left(1-n_{t}^{i} \tau\right)=y_{t} \tau\left[y_{t}\left(1-n_{t}^{i} \tau\right)\right]^{-\theta_{i}} \ln c_{t}^{i}}{-\lambda \gamma\left(n_{t}^{i}\right)^{-\lambda-1}-\theta_{i}\left(y_{t} \tau\right)^{2}\left[y_{t}\left(1-n_{t}^{i} \tau\right)\right]^{-\theta_{i}-1}}
$$

where,

$$
\begin{aligned}
& \frac{\partial \digamma\left(n_{t}^{i}, \theta_{i}\right)}{\partial \theta_{i}}\left\{\begin{array}{rll}
>0 & \text { if } & c_{t}^{i}>1 \\
<0 & \text { if } & c_{t}^{i}<1
\end{array} .\right. \\
& \frac{\partial \digamma\left(n_{t}^{i}, \theta_{i}\right)}{\partial n_{t}^{i}}<0
\end{aligned}
$$

Hence,

$$
\operatorname{sign}\left[\frac{\partial n_{t}^{i}}{\partial \theta_{i}}\right]=\operatorname{sign}\left[\frac{\partial \digamma\left(n_{t}^{i}, \theta_{i}\right)}{\partial \theta_{i}}\right]\left\{\begin{array}{lll}
>0 & \text { if } & c_{t}^{i}>1 \\
<0 & \text { if } & c_{t}^{i}<1
\end{array} .\right.
$$

As follows from the budget constraint $(4) c_{t}^{i} \lesseqgtr 1$ if and only if $n_{t}^{i} \gtreqless\left[1-\left(1 / y_{t}\right)\right] / \tau$. Hence, evaluating $\digamma\left(n_{t}^{i}, \theta_{i}\right)$ at $n_{t}^{i}=\left[1-\left(1 / y_{t}\right)\right] / \tau$ and thus $c_{t}^{i}=1$, it follows that if

$$
\digamma\left(\left[1-\left(1 / y_{t}\right)\right] / \tau, \theta_{i}\right)=\gamma\left(\left[1-\left(1 / y_{t}\right)\right] / \tau\right)^{-\lambda}-y_{t} \tau<0,
$$

then since $\partial \digamma\left(n_{t}^{i}, \theta_{i}\right) / \partial n_{t}^{i}<0$, the level of fertility that will be optimal is $n_{t}^{i}<\left[1-\left(1 / y_{t}\right)\right] / \tau$ and $c_{t}^{i}>1$. Thus,

$$
c_{t}^{i} \gtrless 1 \text { if and only if } \lambda \ln \left[1-\left(1 / y_{t}\right)\right] / \tau \gtrless \ln \left(\gamma / y_{t} \tau\right) \text {, }
$$


i.e.,

$c_{t}^{i}>1$ iff $\left[y_{t} \geq \gamma / \tau\right]$ or $\left[1 /(1-\tau)<y_{t}<\gamma / \tau\right]$ and $\lambda>\ln \left(\gamma / y_{t} \tau\right) / \ln \left(\left[1-\left(1 / y_{t}\right)\right] / \tau\right)$

$c_{t}^{i}<1$ iff $\left[\tilde{c}<y_{t}<1 /(1-\tau)\right]$ or $\left[1 /(1-\tau)<y_{t}<\gamma / \tau\right]$ and $\lambda<\ln \left(\gamma / y_{t} \tau\right) / \ln \left(\left[1-\left(1 / y_{t}\right)\right] / \tau\right)$

Hence the lemma follows (61) and (64). 


\section{References}

[1] Aghion, P. and P. Howitt (1992), "A Model of Growth through Creative Destruction." Econometrica 60, 323-351.

[2] Audretsch, D. B. and R. Thurik (2001), "Linking Entrepreneurship to Growth", OECD Science, Technology and Industry Working Papers, 2001/2, OECD Publishing.

[3] Audretsch, D. B. and Max Keilbach (2005),"Entrepreneurship capital and regional growth" The Annals of Regional Science 39:457-469.

[4] Bar-Shira Z, R.E. Just b, D. Zilberman, (1997), "Estimation of Farmers' Risk Attitude: an Econometric Approach," Agricultural Economics 17, 211-222.

[5] Benjamin J, Li L, Patterson C, Greenberg BD, Murphy DL, and D.H. Hamer (1996), "Population and familial association between the D4 dopamine receptor gene and measures of Novelty Seeking." Nature Genetics 12, 81-84.

[6] Bernardo, A., and I. Welch. (2001), "On the Evolution of Overconfidence and Entrepreneurs." Journal of Economics and Management Strategy 10, 301-330.

[7] Bertocchi, G., "The Law of Primogeniture and the Transition from Landed Aristocracy to Industrial Democracy." Journal of Economic Growth 11, 41-68.

[8] Bisin, A., and T. Verdier (2000), "Beyond the Melting Pot: Cultural Transmission, Marriage, and the Evolution of Ethnic and Religious Traits." Quarterly Journal of Economics $115,955-988$.

[9] Borghans, J.A.M., L. Borghans and B. ter Weel, (2006), "Is There a Link between Economic Outcomes and Genetic Evolution? Cross-Country Evidence from the Major Histocompatibility Complex". Maastricht.

[10] Boserup, E., (1965). The Conditions of Agricultural Progress, (Aldine Publishing Company, Chicago).

[11] Boyd, R., and P.J. Richardson (1985), Culture and the Evolutionary Process (University of Chicago Press, Chicago).

[12] Cavalli-Sforza, L.L., and M.W. Feldman (1981), Cultural Transmission and Evolution: A Quantitative Approach (Princeton University Press, Princeton).

[13] Clark, G. and G. Hamilton (2003), "Survival of the Fittest? Capital, Human Capital, and Reproduction in European Society before the Industrial Revolution." UC Davis.

[14] Cloninger C.R. (1987), "A Systematic Method for Clinical Description and Classification of Personality Variants. A Proposal." Archives of General Psychiatry 44, 573-588.

[15] Cloninger, C. R.; Adolfsson, R.; Svrakic, N. M. (1996), "Mapping Genes for Human Personality." Nature Genetics 12, 3-4.

[16] Dawkins, R. (1989), The Selfish Gene (Oxford University Press, Oxford).

[17] Diamond, J. (1997),.Guns, Germs, and Steel: The Fates of Human Societies.(Norton, New York). 
[18] Ding Y., Chi H., Grady L., Morishima A., Kidd J., Kidd K., Flodman P., Spence A., Schuck S., Swanson J., Zhang Y., Moyzis R. (2002), "Evidence of Positive Selection Acting at the Human Dopamine Receptor D4 Gene Locus." Proceedings of the National Academy of Sciences of the United States of America 99, 309-314.

[19] Doepke, M. (2004), "Accounting for Fertility Decline During the Transition to Growth", Journal of Economic Growth 9: 347-383.

[20] Doepke, M. and F. Zilibotti (2005), "Patience Capital, Occupational Choice, and the Spirit of Capitalism." IIES.

[21] Doepke, M. and F. Zilibotti (2005), "Social Class and the Spirit of Capitalism." Journal of the European Economic Association, 3(2-3), 516-524,

[22] Dohmen T., Falk A., Huffman D., Sunde U., Schupp J., Wagner G. (2005), "Individual Risk Attitudes: New Evidence from a Large, Representative, Experimentally-Validated Survey." Discussion Paper No. 1730, IZA.

[23] Endler, J.A. (1986), Natural Selection in the Wild (Princeton University Press, Princeton).

[24] Ebstein RP, Novick O, Umansky R, Priel B, Osher Y, Blaine, D, Bennett ER, Nemanov L, Katz M, Belmaker RH (1996) "Dopamine D4 receptor (D4DR) exon III polymorphism associated with the human personality trait of Novelty Seeking." Nature Genetics 12, 78-80.

[25] Feinerman E., Finkelstein I., (1996), "Introducing Socioeconomic Characteristics into Production Analysis Under Risk", Agricultural Economics 13,149-161.

[26] Flash Eurobarometer 160, (2004), "Entrepreneurship", EOS Gallup Europe, European Commission (Directorate-General "Enterprises").

[27] Galor, O. (2005), "From Stagnation to Growth: Unified Growth Theory." in P. Aghion and S. Durlauf eds., Handbook of Economic Growth (Elsevier, Holland).

[28] Galor, O., and O. Moav (2002), "Natural Selection and the Origin of Economic Growth." Quarterly Journal of Economics 117, 1133-1192.

[29] Galor, O. and D.N. Weil (2000), "Population, Technology and Growth: From the Malthusian Regime to the Demographic Transition." American Economic Review 110, 806-828.

[30] Grant, B.R., and P.R. Grant (1989), Evolutionary Dynamics of a Natural Population (University of Chicago Press, Chicago).

[31] Grisley W. and Kellog E (1987), "Risk-Taking Preferences of Farmers in Northern Thailand: Measurements and Implications." Agricultural Economics 1, 127-142.

[32] Hansen, G., Prescott, E. (2002). "Malthus to Solow". American Economic Review 92, $1205-1217$.

[33] Hansson, I., and C. Stuart (1990), "Malthusian Selection of Preferences." American Economic Review 80, 529-544.

[34] Harris J.; Vernon P.; D. Boomsma (1998), "The Heritability of Testosterone: A Study of Dutch Adolescent Twins and Their Parents." Behavior Genetics 28, 165-171. 
[35] Heath A. C, Cloninger C. R. , N.G. Martin (1994), "Testing a Model for the Genetic Structure of Personality A Comparison of the Personality Systems of Cloninger and Eysenck." Journal of Personality and Social Psychology, 66, 762-75.

[36] Jones, Garett and W. Joel Schneider (2006) "Intelligence, Human Capital, and Economic Growth: A Bayesian Averaging of Classical Estimates (BACE) Approach." Journal of Economic Growth, 11, 71-93.

[37] Kettlewell, H.B.D. (1973), The Evolution of Melanism (Clarendon Press, Oxford).

[38] Kihlstrom R. and J. Laffont (1979), "A general Equilibrium Entrepreneurial Theory of Firm Formation Based on Risk Aversion." Journal of Political Economy 87, 719-747.

[39] Knight, J. Weir, S. Woldehanna, T. (2003), " The Role of Education in Facilitating RiskTaking and Innovation in Agriculture", Journal of Development Studies 39, 1-22.

[40] Kohler, H., J.L. Rodgers and K. Christensen (1999), "Is Fertility Behavior in our Genes? Findings from a Danish Twin Study." Population and Development Review 25: 253-263.

[41] Koren M. and S. Tenreyro, "Volatilty and Development", forthcoming in the Quarterly Journal of Economics, 122(1), February 2007

[42] Kose S. (2003), "A Psychobiological Model of Temperament and Character: TCI." Yeni Symposium 41 (2): 86-97.

[43] Lagerlof, N., (2003), "From Malthus to Modern Growth: The Three Regimes Revisited." International Economic Review 44, 755-777.

[44] Lagerlof, N., (2005), "Long-Run Trends in Human Body Mass," Department of Economics, York University.

[45] Lagerlof, N., (2006). "The Galor-Weil model revisited: A quantitative exploration". Review of Economic Dynamics 9, 116-142.

[46] Livi-Bacci, M. (1997), A Concise History of World Population (Blackwel, Oxford).

[47] Livingston F, (1958), "Anthropological Implications of Sickle Cell Distribution in West Africa." American Anthropologist 60, 533-562.

[48] Maddison A. (2001), "The World Economy: A Millennia Perspective", Development Centre Studies OECD.

[49] Malthus, T.R. (1798), An Essay on the Principle of Population (printed for J. Johnson, in St. Paul's Church-Yard, London).

[50] Meikle, A.W., J.D. Stringham, D.T. Bishop, D.W. West. 1988. Quantitating Genetic and Nongenetic Factors Influencing Androgen Production and Clearance Rates in Men. Journal of Clinical Endocrinology and Metabolism, 67, 104-109.

[51] Mekel-Bobrov, N., S. L. Gilbert, P. D. Evans, E. J. Vallender, J. R. Anderson, R. R. Hudson, S. A. Tishkoff, and B.T. Lahn (2005), "Ongoing Adaptive Evolution of ASPM, a Brain Size Determinant in Homo sapiens." Science 309, 1720-1722.

[52] Meng X. and N. Qian (2006), "The Long Run Impact of Childhood Malnutrition: Evidence from China's Great Famine," Brown University. 
[53] Miyata S., (2003), "Household's risk attitudes in Indonesian villages", Applied Economics, 573-583.

[54] Mokyr, J. (2006) "Economics and the Biologists, Journal of Economic Literature (forthcoming).

[55] Mokyr, J. (2005), "Natural History and Economic History: Is Technological Change an Evolutionary Process?" Northwestern.

[56] Mokyr, J (1998), "Science, Technology, and Knowledge: What Historians can learn from an evolutionary approach." Max Planck Institute on Evolutionary Economics Working Papers 9803.

[57] Moscardi E and de Janvry A (1977), "Attitudes towards risk among peasants: an econometric approach", American Journal of Agricultural Economics, Vol. 59, No.4 , November (1977) $710-716$.

[58] Nielsen R, Bustamante C, Clark AG, Glanowski S, Sackton TB, et al. (2005), "A Scan for Positively Selected Genes in the Genomes of Humans and Chimpanzees", PLoS Biology, 3(6), e170.

[59] Ofek, H., (2001), Second Nature: Economic origin of Human evolution. Cambridge: Cambridge University Press.

[60] Palacios-Huerta I., Santos T. J., (2004), " A Theory of Markets, Institutions, and Endogenous Preferences", Journal of Public Economics 88, 601-627.

[61] Reznick, David N., Michael J. Bryant, Derek Roff, Cameron K. Ghalambor and Dionna E. Ghalambor (2004), "Effect of Extrinsic Mortality on the Evolution of Senescence in Guppies." Nature 431, 1095-1099.

[62] Robson A., (1996), "A Biological Basis for Expected and Non-Expected Utility." Journal of Economic Theory, 68, 397-424.

[63] Rodgers, J.L., and D. Doughty (2000), "Genetic and Environmental Influences on Fertility Expectations and Outcomes Using NLSY Kinship Data", in: J.L. Rodgers, D.C. Rowe and W.B. Miller, eds., Genetic Influences on Human Fertility and Sexuality (Kluwer, Boston).

[64] Rodgers, J.L., H. Kohler, K. Ohm Kyvik, and K. Christensen (2001), "Behavior Genetic Modeling of Human Fertility: Findings from a Contemporary Danish Twin Study", Demography 38: 29-42.

[65] Saint-Paul, G. (2003), "On Market and Human Evolution" CEPR Discussion Paper No. 3654 .

[66] Schinka J.A, Letsch E.A and F.C. Crawford (2002), "DRD4 and Novelty Seeking: Results of Meta-analyses", American Journal of Medical Genetics 114, 643-648

[67] Schumpeter, J. A. (1934), The Theory of Economic Development. (Cambridge: Harvard University Press).

[68] Spolaore, E. and R. Wacziarg (2005), "The Diffusion of Development," Stanford and Tufts. 
[69] Stallings M.C., Hewitt J.K., Cloninger C.R., Heath A.C. and L.J. Eaves (1996) "Genetic and Environmental Structure of the Tridimensional Personality Questionnaire:three or four Primary Temperament Dimensions" Journal of Personality and Social Psychology $70,127-140$.

[70] Stearns, Stephen C. (1992), The Evolution of Life Histories, (Oxford: Oxford University Press).

[71] Tellegen A, Lykken DT, Bouchard TJ Jr, Wilcox KJ, Segal NL, and S. Rich (1988), "Personality similarity in twins reared apart and together." Journal of Personality and Social Psychology 54, 1031-39.

[72] Van Praag Cramer J. (2001), "The Roots of Entrepreneurship and Labour Demand: Individual Ability and Low Risk Aversion", Economica, 45-62.

[73] Voight, B.F., S. Kudaravalli, (2006), X. Wen, and J.K. Pritchard. "A Map of Recent Positive Selection in the Human Genome." Plos Biology.

[74] Weibull, J., and M. Salomonsson, (2005), "Natural selection and social preferences," Journal of Theoretical Biology

[75] Weisdorf, J. L. (2004), "From Stagnation to Growth: Revisiting Three Historical Regimes." Journal of Population Economics 17, 455-472.

[76] Weismann, A. (1882) Uber die Dauer des Lebens, (Gustav Fischer, Jena, Germany).

[77] Weisenfeld, S.L. (1967), "Sickle Cell Trait in Human Biological and Cultural Evolution", Science 157, 1135-1140.

[78] Westendorp, R.G.J., Kirkwood, T.B.L. (1998), "Human Longevity at the Cost of Reproductive Success," Nature, 396, 743-746.

[79] White R, Stewart T, Hampson E, (2005), "Entrepreneurs and Evolutionary Biology: The Relationship between Testosterone and New Venture Creation". Western Ontario.

[80] Wik M., T. A. Kebede, O. Bergland, H. Stein (2004) "On the Measurement of Risk Aversion from Experimental Data", Applied Economics 36, 2443-2451.

[81] Williams, G. (1957) "Pleiotropy, Natural Selection and the Evolution of Senescence" Evolution 11, 398-411.

[82] Williams P. D. and T. Day (2003) "Antagonistic Pleiotropy, Mortality Source Interactions, and The Evolutionary Theory Of Senescence." Evolution, 57, 1478-1488.

[83] Wilson, E.O. (1975), Sociobiology: The New Synthesis, (Cambridge, Mass.:Harvard University Press). 